\title{
Optimization of the Stability and Reliability of Rotor System by the Methodology of Design Experiments
}

\author{
Brihmat Mostefa $^{1 *}$, Refassi Kaddour ${ }^{1}$, Younes Mimoun ${ }^{2}$, Douroum Embarek ${ }^{3}$, Kouadri Amar ${ }^{4}$ \\ ${ }^{1}$ LMSS Laboratory, Department of Mechanical Engineering, University of Djillali Liabes, Sidi Bel Abbes 22000, Algeria \\ ${ }^{2}$ Department of Electrical Engineering, University of Djillali Liabes, Sidi Bel Abbes 22000, Algeria \\ ${ }^{3}$ Laboratory of Materials and Reactive Systems, LMSR, Djillali Liabes University, Sidi Bel Abbes 22000, Algeria \\ ${ }^{4}$ Gas Turbine Joint Research Team, Faculty of Science and Technology, University of Djelfa, Djelfa 17000, Algeria
}

Corresponding Author Email: mostefa.brihmat@univ-sba.dz

https://doi.org/10.18280/mmep.080219

Received: 1 October 2020

Accepted: 15 January 2021

\section{Keywords:}

Plakett-Burman, hydrodynamic bearings, stability, stiffness, gyroscopic forces, critical rotational speeds

\begin{abstract}
The dynamic behavior of the rotors is influenced by the bearings mounted on them. The aim of this research is to study the effect of the stiffness, shaft diameters and dimensions of lubricated journal bearings on the stability of the system using DOE methodology. We first calculated the values of the real frequency and imaginary frequency of the rotor by the Matlab program, then we prepared a matrix containing forty eight tests according to the Placket Berman plan representing the number of experiments and nine columns representing the factors: the rotor diameters and the dimensions of the hydrodynamic bearing and the system stiffness, to find out the most factors affecting the frequency in The real part or the fictional part, and any of them, affects system stability. The results showed that the diameter D1 has the more significant positive effect on the real part frequency, compared to outer journal diameter $\mathrm{Db}$ that has a negative effect on the imaginary part frequency and vice versa, as affirmed by the plot of principal effects. By with this criterion one can estimate the frequency as well as the mode for which the system will become unstable. On the other hand, a finite element code has been written in MATLAB to know the eigenvalues, and critical velocity that correspond to the speed at which the unbalanced excitation coincides with the eigenvalue. The results of the tests showed that the finite element method (FEM) was very effective studying system stability.
\end{abstract}

\section{INTRODUCTION}

The development of efficient and accurate numerical procedures to analyze the dynamic phenomena involved on rotor-bearing systems have been motivated mainly by the analysis, design and commissioning of high-speed rotating machinery $[1,2]$. In the modeling of rotating machines, some of the main features of the system should be considered, such as gyroscopic effects, rotatory inertia and the bearing contribution. When establishing the stiffness and damping coefficients associated with hydrodynamic rotating bearings in the rotor model, it may be demonstrated that they play an important role in the rotor response.

Statistical experimental design, also known as design of experiments (DOE), is the methodology of how to conduct and plan experiments in order to extract the maximum amount of information with the lowest number of analyses [3]. A désignes experiment is a tool or set of tools used for gathering test data. Typical characteristics of an experimental design are planned testing, data analysis approach, simultaneous factor variability and scientific approach [4]. Various industrial applications relate to rotating machines, such as gas turbines, turbojets, turbochargers, and others. The rotor is the main element which generates vibrations in all rotating machines, particularly during their operations, these vibrations are the results of an unbalance fault [5].
A rotor can be defined as a combination of shaft and multiple discs suspended on rigid or flexible bearings that allow it to rotate freely about a fixed axis. The discs are often considered to be rigid and the shaft, flexible. The calculation and subsequent control of unbalance response amplitude and stability limit speed have always been of utmost importance in all areas related to turbo machinery. This is especially true in the case of high-speed machines where uncontrolled vibration and instability of rotating machinery can lead to catastrophic results. Another crucial demand in modern designs is the need for a higher power-to-weight ratio. Delivering better performance with lighter machines has added advantages of easier maintenance and transport as well. Considering all such requirements, rotors are designed to be lighter, more flexible, and easily operable at higher speeds.

Earliest among the studies on optimization techniques applied in the field of rotor dynamics has been minimizing a single-objective function of the response due to system unbalance. Pilkey et al. [6] employed a more efficient linear programming model as opposed to trial-and-error methods that were prevalent before. Bhat et al. [7] investigated the influence of journal bearing parameters like bearing diameter, clearance, and oil viscosity in optimum rotor design by minimizing unbalance response amplitude in the operating speed range by using the method of feasible directions. Stocki et al. [8] minimized the vibration amplitude of a compressor 
shaft while subject to multiple practical constraints on displacements that caused rubbing effects. Helfrich et al. [9] used optimization techniques to maximize the first critical speed of a multidisc rotor system with bearing and disc dimensions as the design variables. Yucel et al. [10] optimized unbalance response amplitude of a rotor-bearing system experimentally using the Taguchi method to determine the design variables having the greatest influence on the objective function. While the system used in Pilkey et al. [6] and Bhat et al. [7] do not account for mass of the shaft or gyroscopic effects, all the studies discussed above consider optimization of a single-objective function.

Therefore, it's essential to reduce vibrations to ensure safe and stable operation of considered machine. This can be realized by proper investigation of the system dynamics. The modal analysis is carried out to get an idea of the dynamic behavior of the system.

A very basic model of a rotor was provided by Jeffcott [11]. First, he considered three hypotheses which are: (i) the rotor carries a point mass, (ii) axially symmetrical rotor, and (iii) no damping is related to the rotor. Then, the model was extended to take damping into account. Irretier et al. [12] constructed a mathematical formulation for the modal analysis of the entire shaft-rotor system at first as a linear time independent system (LTI) and later as a Linear Time Varying system (LTV). Rotor rotation generates additional forces such as gyroscopic, tangential, and rotating damping forces [13]. Because of the effects of these forces, the structure of system matrices becomes asymmetric and depends strongly on the speed [14].

The stability analysis of symmetrical rotor bearing systems was studied by Laszlo [15] using finite element method, he taken in consideration the internal damping. His findings showed that the whirling motion of the rotor system becomes unstable beyond the critical speed of instability; he found that the rotor stability is enhanced by increasing of bearings damping.

Fegade et al. [16] and Patel et al. [17] in their works, thy studied the harmonic analysis of the rotor to identify the frequency using the variation of the diameter by design optimization (DOE) and by parametric design using ANSYS software. In addition, another study was carried out to develop an alternative procedure called harmonic analysis to identify the frequency of a system through critical speed, amplitude, and phase angle curves using ANSYS.

A study was performed using the Plakett-Burman statistical method on the experimental designs in order to define the influence of the stiffness coefficients on the rotating machines dynamics in particular on the diameters which produce these high frequencies [18]. The factors interactions can affect by increasing or decreasing the principal effects as affirmed by the interaction and surface graphs. Their results show that the inclusion of the stiffness coefficients on the dynamic analysis of rotating machines supported on hydrodynamic bearings play a significant role on the estimation of the unbalance response of rotors.

Naouri Abdallah et al. [19]. In their study, they considered that the dynamic behavior of fluid film bearings is one of the main factors, which affects the rotating machine performances. In this study, a rigid rotor supported by two identical hydrodynamic bearings is taken into consideration. The principal goal of this work is to predict the effect of the damping film of the hydrodynamic bearings on the rotating machines stability.

This paper Concerns the optimization and the modeling of the stability and reliability of operation of a rotor system using the methodology of design of experiments (DOE).

First, we calculated the values of real frequency and imaginary frequency of the rotor by the Matlab program then set up a matrix containing forty eight tests according to the Placket Berman plan which represents the number of experiments and nine columns representing the factors, which are the following the diameters of the rotor, and the dimensions of the hydrodynamic bearing, and the rigidity of the system, in order to know the most influencing factors on the frequency in the real part or the imaginary part, and which of them have an impact on the destabilization of the system. It was found by the results that the factors having a positive effect on the increase in frequency in the real part have a negative effect on the frequency in the imaginary part. Finite element code is written in MATLAB to determine the eigenvalues and eigen vectors. Eigenvalues are calculated in imaginary parts, that show the system natural frequencies, which are used to plot the Campbell diagram. The stability diagram is plotted using the maximum real fraction of all eigenvalues with rotational velocity. Eigenvalues are also used to study the effect of a typical damping factor on rotational speed. These diagrams show that the stability of the system can be studied and the rotational speed stability limit can be determined.

\section{GEOMETRIC CHARACTERISTICS}

Figure 1 illustrates the cross section of a "plain" journal bearing [20]. The bearing main dimensions are: $D_{B}=2 R_{B}$ inner bearing diameter, $D=2 R$-outer journal diameter, $L$ bearing length, $C=R_{B}-R$ - bearing clearance, $e=\overline{o_{B} O_{J}}$ eccentricity, $\phi$ - attitude angle and $h$ - fluid film thickness.

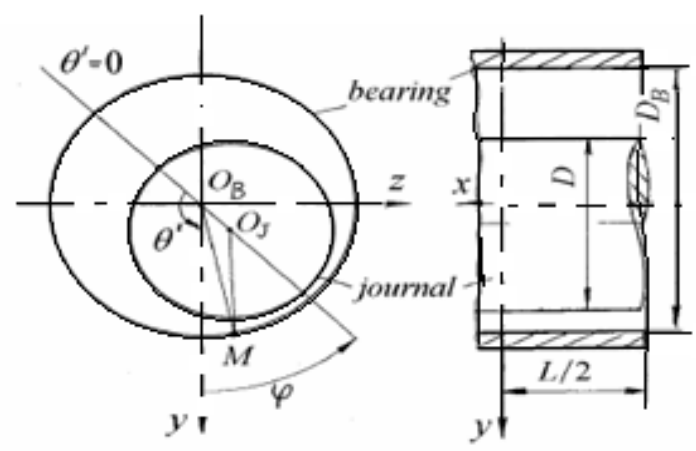

Figure 1. Geometry of a plain cylindrical bearing

It is necessary to present the following dimensionless engineering parameters: $L / D$ - length-to-diameter ratio; $C / R$ clearance ratio; $\varepsilon=e C$ - eccentricity ratio; and $\bar{h}==h / C$ normalized film thickness.

The journal rotates anticlockwise with a constant angular speed $\Omega=2 \pi N(\mathrm{rad} / \mathrm{sec})$, where $N$ represents the journal spin speed in rps.

\section{CONSTITUIVE RELATIONS AND EQUATIONS OF MOTION}

\subsection{Effects of the bearings}

The bearings act as external forces acting on the rotor. They 
are characterized by their stiffness and damping.

$$
\begin{aligned}
& F_{u}=-K_{x x} u-k_{x z} w-C_{x x} \dot{u}-C_{x z} \dot{w} \\
& F_{w}=-K_{z z} w-k_{z x} u-C_{z z} \dot{w}-C_{z x} \dot{u}
\end{aligned}
$$

In matrix form:

$$
[F]=-[K] \delta-[C] \delta
$$

With stiffness With bearing damping

$$
[K]=\left[\begin{array}{cccc}
k_{x x} & 0 & k_{x z} & 0 \\
0 & 0 & 0 & 0 \\
k_{z x} & 0 & k_{z z} & 0 \\
0 & 0 & 0 & 0
\end{array}\right]\left[C_{d}\right]=\Omega\left[\begin{array}{cccc}
0 & 0 & 0 & 0 \\
0 & 0 & 0 & 0 \\
0 & 0 & 0 & -I_{D y} \\
0 & 0 & I_{D y} & 0
\end{array}\right]
$$

\subsection{Equations of the rotor movement}

The application of the Lagrange equations on the different energies gives:

\section{For the shaft:}

$$
\frac{d}{d t}\left(\frac{\partial T}{\partial \dot{\delta}}\right)-\frac{\partial T}{\partial \delta}=\left(M+M_{S}\right) \ddot{\delta}+C \dot{\delta}
$$

With mass and gyroscopic effect matrices. The mass matrix is symmetrical. The matrix $\mathrm{C}$ is antisymmetric.

$$
\frac{\partial U}{\partial \delta}=\left(k_{c}+k_{F}\right) \delta
$$

$\mathrm{K}_{\mathrm{c}}$ takes into account the effect of shear, $\mathrm{K}_{\mathrm{F}}$ is due to axial forces.

\section{For the disc:}

$$
\begin{gathered}
\frac{d}{d t}\left(\frac{\partial t}{\partial \dot{\delta}}\right)-\frac{\partial T}{\partial \delta}=M_{d} \ddot{\delta}+C_{d} \dot{\delta} \\
{\left[M_{d}\right]=\left[\begin{array}{cccc}
k_{x x} & 0 & 0 & 0 \\
0 & M_{D} & 0 & 0 \\
k_{z x} & 0 & I_{D x} & 0 \\
0 & 0 & 0 & I_{D z}
\end{array}\right][C]=\left[\begin{array}{cccc}
c_{x x} & 0 & c_{x z} & 0 \\
0 & 0 & 0 & 0 \\
c_{z x} & 0 & c_{z z} & 0 \\
0 & 0 & 0 & 0
\end{array}\right]}
\end{gathered}
$$

From equations of the shaft, the disk and the bearings the equation of the rotor motion is written in the form:

$$
M \ddot{\delta}+C(\Omega) \delta+\dot{K} \delta=0
$$

The mass matrix contains the mass of the rotor and disks. The stiffness matrix contains the stiffness of the shaft and bearings. $\mathrm{C}$ contains the gyroscopic effect of the shaft and the disks and the matrix damping of the bearings.

The assembly of the displacement vectors of all the rotor nodes into finite elements gives the global displacement vector $\{\mathrm{X}\}$ and the global matrices. In this case the equation of rotor motion becomes:

$$
[M]\{\ddot{X}\}+\left(\Omega\left[C_{g}\right]+\left[C_{p}\right]\right)\{\dot{X}\}+\left(\left[K_{r}\right]+\left[K_{p}\right]\right)\{X\}=0
$$

The gyroscopic effect of the shaft and disks and the matrix damping of the bearings. F can represent unbalance or any other external forces.

\subsection{Some important phenomena in rotor dynamics}

We will now consider some important phenomena of rotor dynamics, and see in particular the concepts of critical velocities and instability related to rotational damping and the role that differences in rotor dynamics play.

\section{- Critical speeds}

The critical velocity corresponds with the speed at which the unbalanced excitation coincides with one of the natural frequencies of the system. In machines consisting of organs with significant moments of polar inertia, we observe a strong dependence on eigen patterns versus rotational velocity due to gyroscopic effects. Thus, we observe the duality of the eigen patterns of the system (in the case of the axial symmetry system) due to the gyroscopic forces as follows:

- (FW) as the rotor rotates in the same direction as it rotates. Then, under gyroscopic effects, the associated resonant frequency increases and this is called "direct precession".

- (BW), where the rotor rotates in the opposite direction to its preliminary motion, resulting in a softening effect and thus a decrease in the critical velocity and this is called the "retrograde precession".

\section{- Instability due to rotating damping}

In the study of stability of rotating machines where damping corresponds to one of the determinants of sizing systems, damping can be responsible for unstable phenomena at high speed, which may lead to rupture of rotor components. In order to ensure system integrity, the damping ratios on both fixed and moving parts must be estimated.

\section{- Stability analysis}

Stability analysis in the study of the vibrational and dynamic behavior of a flexible rotor is essential because it is considered a dynamic system governed by systems of differential equation. The definition of stability covers Leibunov's definition of equilibrium stability analysis and the Poincaré definition of the concept of orbital stability [21].

We can know the limits of dynamic system instability and in particular in rotor dynamics through the following techniques:

- Sign of the real part of the complex eigenvalues of the equation system in free motion. If the eigenvalues is given by $\mathbf{s}=\mathbf{- a} \pm \mathbf{j b}$, the only instability is determined when a becomes negative (real positive part), with this criterion one can estimate the frequency as well as the mode for which the system will become unstable. The Routh-Hrwitz criterion makes it possible to analyze the stability of autonomous systems [22].

The use of this criterion is interesting for systems with a few degrees of freedom, since the analytical expressions of the characteristic polynomial associated with the perturbed 
motion can be inferred. However, it becomes complicated for systems that include a large number of degrees of freedom. Additionally, this criterion does not provide an instability frequency.

These two criteria studying the stability of a dynamic system restrict particular cases, or when they are described by linear models, for example R. Sino [23]. In the subject of his thesis, he uses these two methods to study and analyze the stability of a rotor due to rotating damping. A more general method is based on Floquet's theory.

- Floquet's theory allows us to analyze, in the linear sense, the stability of systems with periodic coefficients [21]. The first step of analysis consists in applying a vector of the periodic solution $\mathrm{S} p$ to a small disturbance $\delta \mathrm{s}$. This brings the system to a new state of equilibrium. The second, we apply a first order Taylor expansion to the neighborhood of $\mathrm{S} p$ to estimate the nonlinear forces in $(\mathrm{s} p+\delta \mathrm{s}, \dot{\mathrm{s}} \mathrm{p}+\delta \cdot \mathrm{s}, \mathrm{s} \cdot+\delta \cdot$ $\mathrm{s})$ in order to make the system linear. This technique is frequently used in the dynamic analysis of rotating structures, particularly in the dynamics of nonlinear rotors (see, for example, the work of Dugundji and Wendell [24]. On the stability analysis of a wind turbine and the analysis of the stabilities of a cracked rotor by Meng and Gasch [25]).

\section{METHODOLOGY}

The main objective of this work is to model and optimize the operation of the rotor system using DOE methodology and to know the gyroscopic effect on the subjective values of the rotor-bearing systems through the Campbell scheme, and to calculate the imbalance responses mainly during the passage of critical velocity. In the use of finite element method. We designed a mathematical model under the rotor kit name in the matlab program that contains the engineering data for the rotor group element (tree data, disk data, and engineering data for the rotor group component.

In addition to the stiffness and damping matrices in the form of a group of nodes and elements to calculate the values of hardness and the imaginary and real frequency in the presence of speed 0-10000 rpm. This calculation mode should be able to give the geometry of the rotor in finite elements. The search for eigenvalues is an essential process in the study of rotor dynamics.

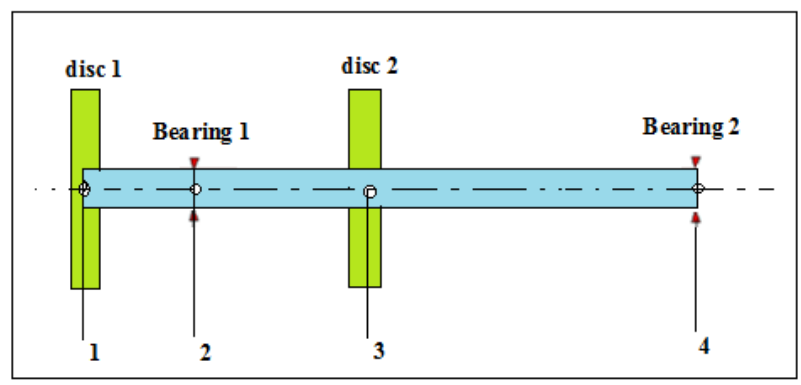

Figure 2. Schematic model of the used model of rotor kit

\section{- $\quad$ Rotor Kit}

The used model is a rotor kit with a length of $0.42 \mathrm{~m}$ as shown in Figure 2. A mass of $1.415 \mathrm{~kg}$ is mounted on the shaft which is supported by two bearings respectively $0.09(\mathrm{~m})$ and $0.42(\mathrm{~m})$ apart from the left end. four stations are considered during harmonic analysis as shown in Figure 1, where station numbers denote different nodes in the model (1) Disc, (2) First bearing node, (3) Disk, (4) Second bearing. For the distributed rotor and the concentrated disc (1), the material density is 7850 $\mathrm{kg} / \mathrm{m}^{3}$ and the modulus of elasticity is $2.06 \mathrm{E} 11 \mathrm{~N} / \mathrm{m}^{2}$. with a mass of $0.81 \mathrm{~kg}$, disk (4) with a mass of $0.6050 \mathrm{~kg}$ polar inertia $(5.783 \mathrm{e}-4,0,4.320 \mathrm{e}-4) \mathrm{kg} \cdot \mathrm{m}^{2}$ and diametral inertia $(3.357 \mathrm{e}-4,0,2.433 \mathrm{e}-4) \mathrm{kg} \cdot \mathrm{m}^{2}$.

\section{Calculation of real and imaginary system frequency values}

A mathematical model was designed under the name of rotor kit using Matlab which includes the data of each element of the rotor kit (shaft, disc, and bearing), and also the stiffness and damping matrices in the form of a set of nodes and elements were used to determine the values of the stiffness and the real and imaginary frequency at a speed interval ranging from 0 to $10,000 \mathrm{rpm}$ (Table 1).

Table 1. Geometric data of rotor-bearing element

\begin{tabular}{c|c|c|c|c}
\hline $\begin{array}{c}\text { Element } \\
\text { Node } \\
\text { No }\end{array}$ & $\begin{array}{c}\text { Node } \\
\text { Location } \\
(\mathbf{c m})\end{array}$ & $\begin{array}{c}\text { Bearing } \\
\text { and } \\
\text { Disk }\end{array}$ & $\begin{array}{c}\text { Inner } \\
\text { Diameter } \\
(\mathbf{c m})\end{array}$ & $\begin{array}{c}\text { Outer } \\
\text { Diameter } \\
(\mathbf{c m})\end{array}$ \\
\hline 1 & 0 & disc & 0 & 0.009525 \\
\hline 2 & 0.09 & Bearing & 0 & 0.009525 \\
\hline 3 & 0.22 & disc & 0 & 0.009525 \\
\hline 4 & 0.42 & Bearing & 0 & 0.009525 \\
\hline
\end{tabular}

\section{RESULTS AND DISCUSSION}

\subsection{Response}

The response chosen is the real frequency and the imaginary frequency of a rotor system - bearings, calculated by matlab software.

\subsection{Determination of factors and field of study}

The factors examined in this study are:

- The diameters of the rotor kit d1, d2, d3.d4.

- The dimensions of the hydrodynamic bearings

$\mathrm{Lb}=$ length of bearings $[\mathrm{m}]$.

$\mathrm{Db}=$ outer journal diameter $[\mathrm{m}]$.

$\mathrm{Cb}=$ bearing cleareance $[\mathrm{m}]$.

- The shaft is mounted on two fluid film bearings where the stiffness (Kyy, Kzz) was determined using Matlab software.

$-\mathrm{Kyz}=\mathrm{Kyz}=0$.

- The components of damping are taken as: $\mathrm{Czz}=\mathrm{Cyy}=61$, $4000(\mathrm{Ns} / \mathrm{m})$. The imbalance response for a counted disc center eccentricity of $0.635(\mathrm{~cm})$ at station (2) was estimated for a speed interval of 0 to $10000 \mathrm{rpm}$.

\subsection{Choice of the experimental design}

First, a screening plan is used. This is a first degree plan which allows you to sort the factors by highlighting the most influential. We chose the Plackett-Burman plan because it is generally the most used in similar studies due to its economy in terms of number of tests.

The nine factors studied and their field of study were grouped together in Table 2 
Table 2. Caption

\begin{tabular}{ccccc}
\hline \multirow{2}{*}{ Factors } & \multirow{2}{*}{ Symbol } & Units & \multicolumn{2}{c}{ Levels } \\
\hline The diameters & $\mathrm{d} 1=\mathrm{d} 2=\mathrm{d} 3=\mathrm{d} 4$ & $(\mathrm{~m})$ & & \\
The & & & & \\
dimensions of & $\mathrm{Lb}$ & $(\mathrm{m})$ & 0.045 & 0.050 \\
the & $\mathrm{Db}$ & $(\mathrm{m})$ & 0.09 & 0.10 \\
hydrodynami & $\mathrm{Cb}$ & $(\mathrm{m})$ & 0.00005 & 0.00009 \\
c bearings & & & & \\
Stiffness & $\mathrm{Kyy}=\mathrm{Kzz}$ & $\mathrm{Ns} / \mathrm{m}$ & 0 & $2,2 \mathrm{e} 5$ \\
\hline
\end{tabular}

\section{PLACKETT-BURMAN SCREENING PLAN}

\subsection{Carrying out the tests}

The tests are conducted according to the Plackett-Burman plan for the 9 factors. The experiments took place according to the matrix of this plan. It represents the fixing of factors at different levels, as shown in Table 3.

Table 3. Plackett-Burman plan based on the experimental matrix

\begin{tabular}{|c|c|c|c|c|c|c|c|c|c|c|c|}
\hline & $d 1$ & $d 2$ & $d 3$ & $d 4$ & $L b$ & $\mathrm{Cb}$ & $D b$ & Kyy & $K z z$ & FRQ img & FRQ real \\
\hline 1 & 0.009475 & 0.009475 & 0.009575 & .009475 & 0.045 & 0.1 & .00009 & $2.2 \mathrm{E}+05$ & $0.0 \mathrm{E}+00$ & 16.463 & 310.192 \\
\hline 2 & 009575 & 0.009475 & 0.009575 & .009575 & 0.05 & 0.1 & .00009 & $0.0 \mathrm{E}+00$ & $0.0 \mathrm{E}+00$ & 44.0043 & 11.976 \\
\hline 3 & 0.009575 & 0.009575 & 0.009575 & 0.009575 & 0.045 & 0.1 & .00009 & $2.2 \mathrm{E}+05$ & $2 \mathrm{E}+05$ & 145.212 & 4.0174 \\
\hline 4 & 0.009575 & .009475 & 0.009575 & 0.009475 & 0.045 & 0.09 & .00009 & $2.2 \mathrm{E}+05$ & $.0 \mathrm{E}+00$ & 16.463 & 310.263 \\
\hline 5 & 0.009575 & 0.009475 & 0.009475 & 009575 & 0.05 & 0.1 & .00009 & $0.0 \mathrm{E}+00$ & $2.2 \mathrm{E}+05$ & 16.617 & 279.268 \\
\hline 6 & 0.009475 & 0.009475 & 0.009475 & 0.009575 & 0.05 & 0.09 & 0.00009 & $2.2 \mathrm{E}+05$ & $0.0 \mathrm{E}+00$ & 16.616 & 323.984 \\
\hline 7 & 0.009575 & 0.009475 & 0.009475 & .009475 & 0.045 & 0.1 & .00005 & $0.0 \mathrm{E}+00$ & $.0 \mathrm{E}+00$ & 44.5628 & 325.573 \\
\hline 8 & 0.009475 & .009575 & 0.009475 & .009475 & 0.045 & 0.09 & 0.00009 & $2.2 \mathrm{E}+05$ & $.0 \mathrm{E}+00$ & & 324.338 \\
\hline 9 & 0.009575 & 0.009575 & 0.009575 & 009475 & 0.045 & 0.09 & 0.00005 & $2.2 \mathrm{E}+05$ & $.0 \mathrm{E}+00$ & 16.234 & 310.591 \\
\hline 10 & 0.009475 & 0.009475 & 0.009575 & 0.009575 & 0.05 & 0.1 & 0.00005 & $2.2 \mathrm{E}+05$ & $2.2 \mathrm{E}+05$ & 142.206 & 13.7369 \\
\hline 11 & 0.009475 & .009475 & 0.009475 & 009475 & 0.05 & 0.09 & .00005 & $0.0 \mathrm{E}+00$ & $.0 \mathrm{E}+00$ & 44.5475 & 325.565 \\
\hline 12 & 0.00 & 9575 & 0.009475 & 009575 & 0.045 & 0.09 & & $2.2 \mathrm{E}+05$ & $.2 \mathrm{E}+05$ & & 02 \\
\hline 13 & 0.009475 & 009575 & 0.009575 & 009475 & 0.05 & 0.1 & .00005 & $0.0 \mathrm{E}+00$ & $2 \mathrm{E}+05$ & 16.236 & 310.516 \\
\hline 14 & & & & & 0.045 & 0.09 & & $2.2 \mathrm{E}+05$ & $2 \mathrm{E}+05$ & & \\
\hline 15 & 0.009475 & 0.009475 & 0.009575 & 0.009575 & 0.05 & 0.09 & 0.00009 & $0.0 \mathrm{E}+00$ & $2.2 \mathrm{E}+05$ & 16.463 & 310.192 \\
\hline 16 & 0.009 & 75 & 009 & 75 & 0.045 & 0.1 & 09 & $0.0 \mathrm{E}+00$ & $2 \mathrm{E}+05$ & & \\
\hline 17 & 0.009575 & 0.009575 & 0.009575 & 0.009575 & 0.045 & 0.09 & 0.00005 & $0.0 \mathrm{E}+00$ & $0.0 \mathrm{E}+00$ & 16.234 & 310.591 \\
\hline 18 & 0.009575 & 575 & 09475 & 009575 & 0.05 & 0.09 & 00005 & $2.2 \mathrm{E}+05$ & $0.0 \mathrm{E}+00$ & & 409 \\
\hline 19 & 0.009575 & 0.009575 & 0.009575 & 009575 & 0.05 & 0.09 & 0.00005 & $0.0 \mathrm{E}+00$ & $0.0 \mathrm{E}+00$ & 44.4545 & 312.228 \\
\hline 20 & 0.009475 & 475 & 09575 & 575 & 0.045 & 0.1 & 00005 & $2.2 \mathrm{E}+05$ & $.0 \mathrm{E}+00$ & & 192 \\
\hline 21 & 0.009475 & 9575 & 0.009475 & 9475 & 0.05 & 0.1 & 09 & $0.0 \mathrm{E}+00$ & $2.2 \mathrm{E}+05$ & 16. & 324.338 \\
\hline 22 & 0.005 & 475 & 09475 & 475 & 0.05 & 0.1 & 05 & $2.2 \mathrm{E}+05$ & $0.0 \mathrm{E}+00$ & & 984 \\
\hline 23 & 0.009575 & 475 & 009475 & 9575 & 0.05 & 0.1 & & $2.2 \mathrm{E}+05$ & $0.0 \mathrm{E}+00$ & & 052 \\
\hline 24 & 0.009475 & 9475 & 0.009575 & 009475 & 0.045 & 0.09 & 0.00005 & $2.2 \mathrm{E}+05$ & $2.2 \mathrm{E}+05$ & 142 & 369 \\
\hline 25 & 0.009475 & 575 & 009475 & 09475 & 0.045 & 0.1 & & $0.0 \mathrm{E}+00$ & $2.2 \mathrm{E}+05$ & & \\
\hline 26 & 0.009575 & 475 & 009475 & 9575 & 0.045 & 0.09 & 00009 & $2.2 \mathrm{E}+05$ & $2 \mathrm{E}+05$ & 144 & 962 \\
\hline 27 & 75 & 475 & 009475 & & 0.0 & & & 0 & $\mathrm{OE}+$ & & \\
\hline 28 & 0.009 & 475 & 09575 & 175 & 0.05 & 0.09 & 05 & $2.2 \mathrm{E}+05$ & $2 \mathrm{E}+05$ & & 185 \\
\hline 29 & & & & & & & & & $0 \mathrm{E}+00$ & & \\
\hline 30 & 75 & 475 & 09575 & 75 & 0.045 & 01 & & $0 \mathrm{E}+00$ & $0.0 \mathrm{E}+00$ & & 966 \\
\hline 31 & & & & & & 0.09 & & $0 \mathrm{E}+00$ & $2 \mathrm{E}+05$ & & 984 \\
\hline 32 & 0.009475 & 0.009475 & 0.009475 & 0.009575 & 0.05 & 0.09 & & $0.0 \mathrm{E}+00$ & $2.2 \mathrm{E}+05$ & & 323.984 \\
\hline 33 & 0.009575 & 9575 & 0.009475 & 0.009575 & 0.045 & 0.1 & 0.00005 & $0.0 \mathrm{E}+00$ & $.0 \mathrm{E}+00$ & 44.9909 & 325.855 \\
\hline 34 & 0.009475 & 0.009575 & 0.009475 & 09475 & 0.05 & 0.1 & & $2.2 \mathrm{E}+05$ & $0.0 \mathrm{E}+00$ & & 324.338 \\
\hline 35 & 0.009575 & 575 & 0.009475 & 0.009475 & 0.05 & 0.09 & 005 & $2.2 \mathrm{E}+05$ & $2.2 \mathrm{E}+05$ & 144 & 962 \\
\hline 36 & 0.009575 & & 009575 & & & 0.09 & & $0.0 \mathrm{E}+00$ & $2.2 \mathrm{E}+05$ & & 263 \\
\hline 37 & 0.009475 & 575 & 09575 & 475 & 0.045 & 0.1 & 05 & $0.0 \mathrm{E}+00$ & $2.2 \mathrm{E}+05$ & 16. & 324.338 \\
\hline 38 & 0.009575 & 0.009575 & 0.009475 & 0.009575 & 0.05 & 0.1 & 0.00009 & $2.2 \mathrm{E}+05$ & $0.0 \mathrm{E}+00$ & 16.396 & 324.409 \\
\hline 39 & 0.009475 & 0.009575 & 0.009575 & 0.009575 & 0.045 & 0.1 & 0.00005 & $2.2 \mathrm{E}+05$ & $0.0 \mathrm{E}+00$ & 16.236 & 310.516 \\
\hline 40 & 0.009575 & 0.009575 & 0.009475 & 0.009575 & 0.045 & 0.1 & 0.00005 & $0.0 \mathrm{E}+00$ & $2.2 \mathrm{E}+05$ & 16.396 & 324.409 \\
\hline 41 & 0.009575 & 0.009475 & 0.009475 & 0.009475 & 0.05 & 0.1 & 0.00005 & $2.2 \mathrm{E}+05$ & $2.2 \mathrm{E}+05$ & 144.574 & 13.9962 \\
\hline 42 & 0.009475 & & & & & & & $0.0 \mathrm{E}+00$ & $0.0 \mathrm{E}+00$ & & 312.217 \\
\hline 43 & 0.009475 & 0.009575 & 0.009575 & 0.009575 & 0.05 & 0.09 & 0.00009 & $2.2 \mathrm{E}+05$ & $2.2 \mathrm{E}+05$ & 142.457 & 13.6378 \\
\hline 44 & 0.009575 & & 0.009575 & & & 0.1 & & $2.2 \mathrm{E}+05$ & $2.2 \mathrm{E}+05$ & 145.563 & 14.1185 \\
\hline 45 & 0.009475 & 0.009575 & 0.009575 & 0.009575 & 0.05 & 0.1 & 0.00005 & $0.0 \mathrm{E}+00$ & $2.2 \mathrm{E}+05$ & 44.4388 & 312.217 \\
\hline 46 & 0.009575 & 0.009575 & 0.009575 & 0.009475 & 0.05 & 0.1 & & $2.2 \mathrm{E}+05$ & $2.2 \mathrm{E}+05$ & 145.212 & 14.0174 \\
\hline 47 & 0.009575 & 0.009475 & 0.009575 & 0.009575 & 0.045 & 0.09 & 0.00009 & $0.0 \mathrm{E}+00$ & $0.0 \mathrm{E}+00$ & 44.0043 & 311.976 \\
\hline 48 & 0.009575 & 0.009575 & 0.009475 & 0.009475 & 0.045 & 0.09 & 0.00009 & $0.0 \mathrm{E}+00$ & $0.0 \mathrm{E}+00$ & 44.9909 & 325.855 \\
\hline
\end{tabular}




\section{STATISTICAL ANALYSIS OF THE RESULTS}

The processing of the experimental data was carried out by linear regression multiple using the MINITAB17 software.

\subsection{Graphic representation of effects}

This diagram (Figure 3) makes it possible to extract the most important parameters. Among all the factors studied and at the chosen confidence level $(\alpha=0.05)$, the strong factors $(\mathrm{kzz})$ and (kyy) appear to be very influential factors, kzz, kyy having the most significant positive effect in the imaginary part frequency and affects negatively the frequency in real part.

\section{A. Pareto chart:}
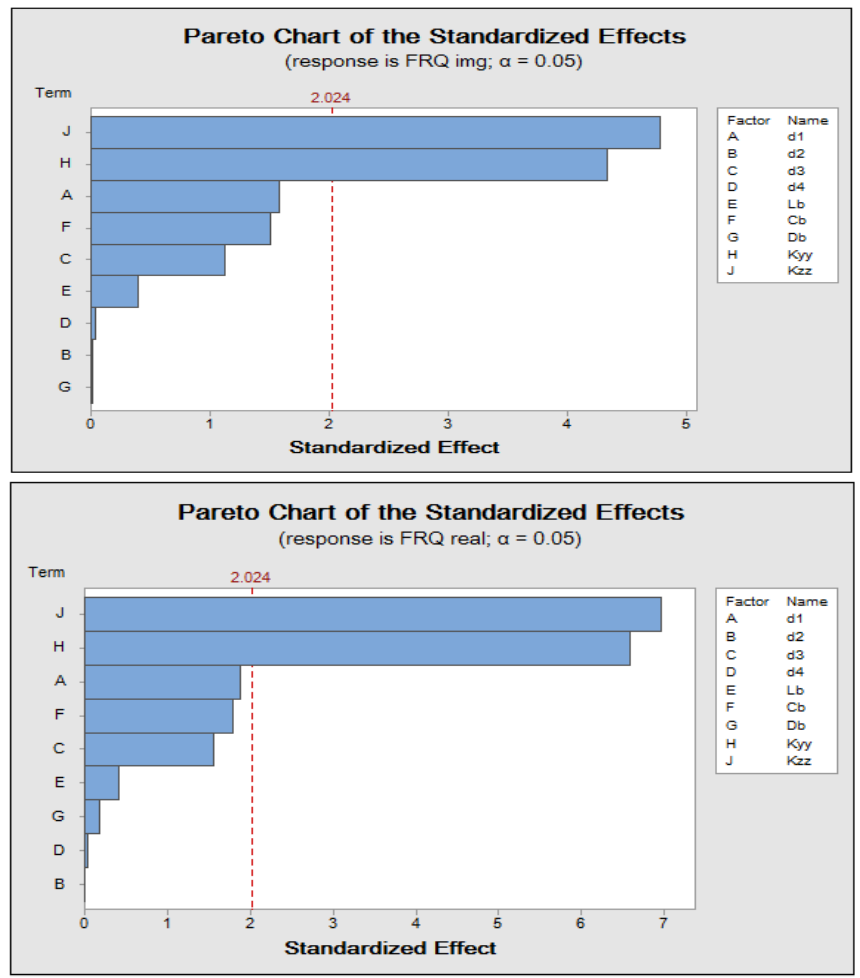

Figure 3. Pareto plot of normalized effects

Figure 4 reveals that kzz and kyy has the greatest significant positive effect on the rightmost imaginary frequency of the response line. However, the figure reveals a significant reduction effect of kzz and kyy on the real frequency of its effect is positioned to the left of the answer line.

\section{B. Pareto plot of normalized}

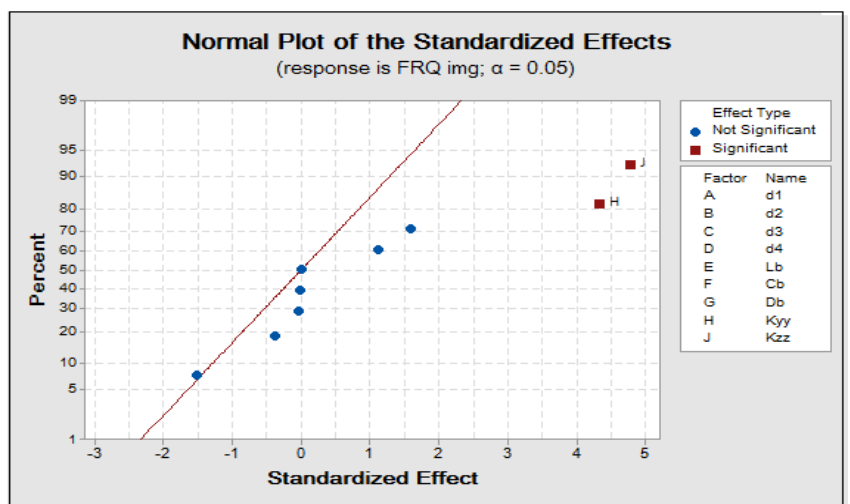

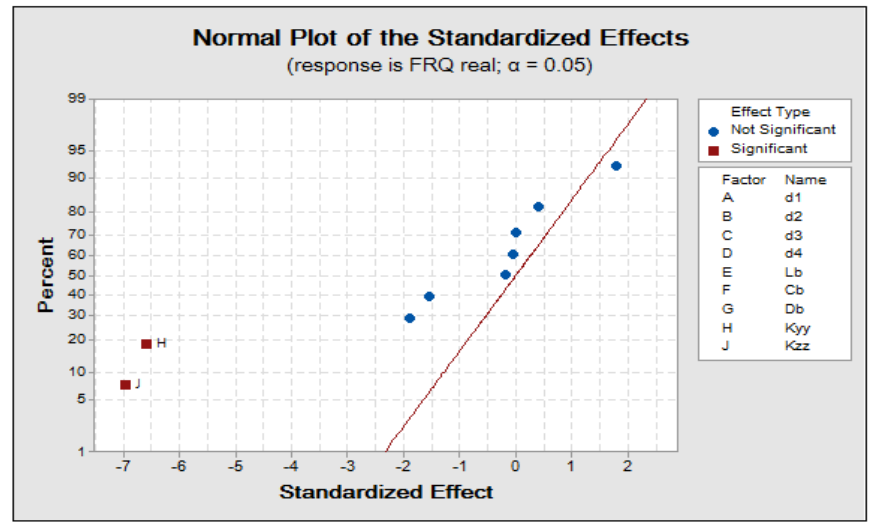

Figure 4. Pareto plot of normalized effects

\section{Main effects diagram}

The main effects diagram tells us about the simultaneous influence of all factors on the frequency. We can from this diagram (Figure 5) conclude that the stiffness kzz and kyy are the most influential factors positively on the imaginary part frequency, and negatively influential on the real part frequency.
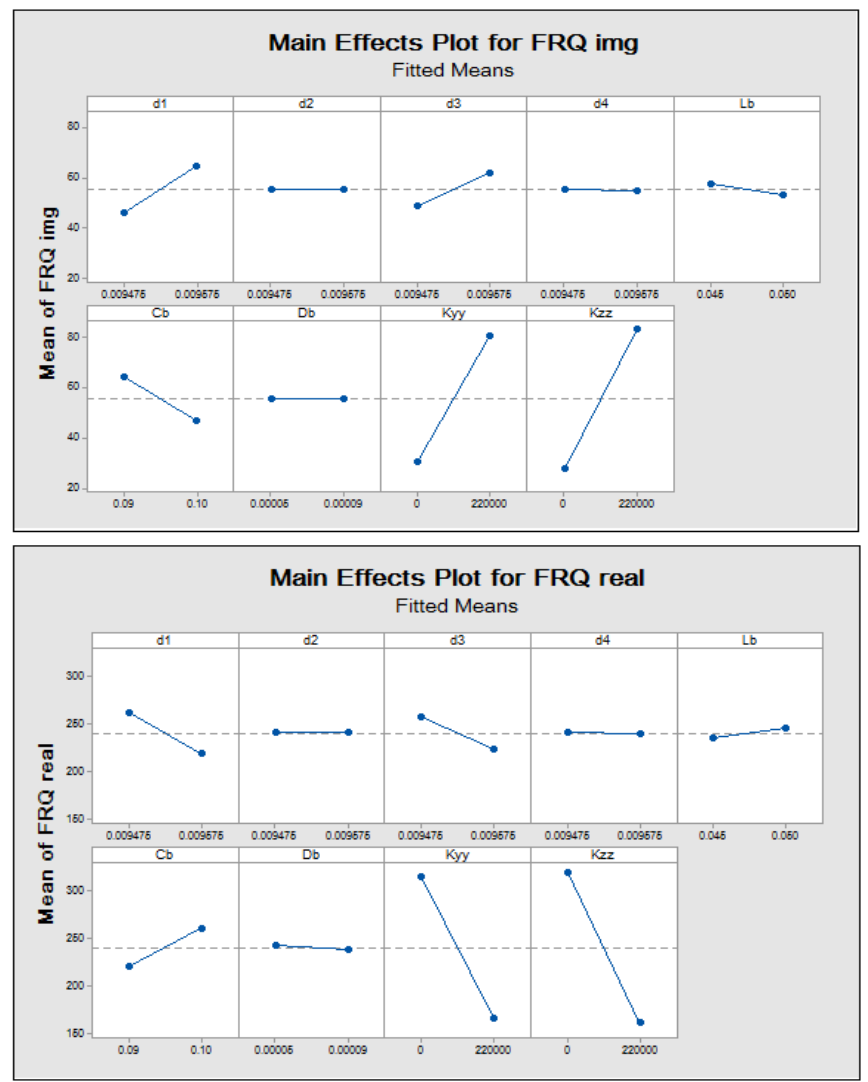

Figure 5. Diagram of the main effects on frequency imaginary- real

\subsection{Determination of significant effects and coefficients of the model}

The effects values and the coefficients of regression of the model are given as bellow in Tables 4 and 5 . 
Table 4. Factorial Regression: FRQ img versus d1; d2; d3; d4; Lb; Cb; Db; Kyy; Kzz

\begin{tabular}{c|c|c|c|c|c}
\hline Source & DF & Adj SS & Adj MS & F-Value & P-Value \\
\hline Model & 9 & 71923 & 7991.5 & 5.07 & 0.000 \\
\hline Linear & 9 & 71923 & 7991.5 & 5.07 & 0.000 \\
\hline D1 & 1 & 3984 & 3984.4 & 2.53 & 0.120 \\
\hline D2 & 1 & 0 & 0.2 & 0.00 & 0.991 \\
\hline D3 & 1 & 1986 & 1985.5 & 1.26 & 0.269 \\
\hline D4 & 1 & 2 & 2.2 & 0.00 & 0.970 \\
\hline Lb & 1 & 240 & 239.7 & 0.15 & 0.699 \\
\hline Cb & 1 & 3577 & 3577.1 & 2.27 & 0.140 \\
\hline Db & 1 & 0 & 0.2 & 0.00 & 0.992 \\
\hline kyy & 1 & 29663 & 29662.7 & 18.80 & $\mathbf{0 . 0 0 0}$ \\
\hline kzz & 1 & 36092 & 36092.3 & 22.88 & $\mathbf{0 . 0 0 0}$ \\
\hline error & 38 & 59946 & 1577.5 & & \\
\hline Total & 47 & 131869 & & & \\
\hline
\end{tabular}

Model Summary

$\begin{array}{llcc}\text { S } & \text { R-sq } & \text { R-sq (adj) } & \text { R-sq (pred) } \\ 39.7180 & 54.54 \% & 43.77 \% & 27.61 \%\end{array}$

Table 5. Factorial Regression: FRQ real versus $\mathrm{d} 1$; $\mathrm{d} 2$; d3; d4; Lb; Cb; Db; Kyy; Kzz

\begin{tabular}{l|c|c|c|c|c}
\hline Source & DF & Adj SS & Adj MS & F-Value & P-Value \\
\hline Model & 9 & 595380 & 66153 & 10.83 & 0.000 \\
\hline Linear & 9 & 595380 & 66153 & 10.83 & 0.000 \\
\hline D1 & 1 & 21791 & 21791 & 3.57 & 0.067 \\
\hline D2 & 1 & 0 & 0 & 0.00 & 0.999 \\
\hline D3 & 1 & 14753 & 14753 & 2.42 & 0.128 \\
\hline D4 & 1 & 12 & 12 & 0.00 & 0.965 \\
\hline Lb & 1 & 1032 & 1032 & 0.17 & 0.683 \\
\hline Cb & 1 & 19436 & 19436 & 3.18 & 0.082 \\
\hline Db & 1 & 187 & 187 & 0.03 & 0.862 \\
\hline kyy & 1 & 264891 & 264891 & 43.38 & $\mathbf{0 . 0 0 0}$ \\
\hline kzz & 1 & 296031 & 296031 & 48.48 & $\mathbf{0 . 0 0 0}$ \\
\hline error & 38 & 232052 & 6107 & & \\
\hline Total & 47 & 827431 & & & \\
\hline & & & &
\end{tabular}

Summary of model

$\begin{array}{clrc}\text { S } & \text { R-sq } & \text { R-sq (adj) } & \text { R-sq (pred) } \\ 78.1449 & 71.96 \% & 65.31 \% & 55.35 \%\end{array}$

Table 6. The used Runs in DOE

\begin{tabular}{|c|c|c|c|c|c|c|c|c|c|c|c|}
\hline & $d 1$ & $d 2$ & $d 3$ & $d 4$ & $L b$ & $\mathrm{Cb}$ & $\mathrm{Db}$ & Kyy & $K z z$ & FRQ img & FRQ real \\
\hline 1 & 0.009475 & .009475 & 0.009475 & .009575 & 0.045 & 0.09 & 0.00009 & $0.0 \mathrm{E}+00$ & $2.2 \mathrm{E}+05$ & 16.616 & 323.984 \\
\hline 2 & .009475 & .009575 & .009575 & .009475 & 0.05 & 0.09 & .00009 & $2.2 \mathrm{E}+05$ & $0.0 \mathrm{E}+00$ & 439 & 2.217 \\
\hline 3 & 0.009475 & .009475 & .009575 & 009575 & 0.045 & 0.09 & 0.00005 & $2.2 \mathrm{E}+05$ & $2.2 \mathrm{E}+05$ & 142.46 & 13.6378 \\
\hline 4 & 0.009575 & .009475 & .009575 & 009475 & 0.045 & 0.1 & 0.00009 & $2.2 \mathrm{E}+05$ & $2.2 \mathrm{E}+05$ & 144.9 & 3.8962 \\
\hline 5 & 0.009475 & .009475 & 009575 & 009575 & 0.05 & 0.1 & 0.00005 & $0.0 \mathrm{E}+00$ & $2.2 \mathrm{E}+05$ & 44.439 & 312.217 \\
\hline 6 & 0.009575 & 009475 & 09475 & 009475 & 0.05 & .1 & .00009 & $0.0 \mathrm{E}+00$ & $2.2 \mathrm{E}+05$ & 16.463 & 263 \\
\hline 7 & 0.009575 & .009575 & 0.009575 & 009475 & 0.05 & 0.1 & 0.00005 & $0.0 \mathrm{E}+00$ & $0.0 \mathrm{E}+00$ & 44.455 & 62.112 \\
\hline 8 & 0.009475 & 009575 & 009475 & 009475 & 0.05 & 0.1 & 0.00005 & $2.2 \mathrm{E}+05$ & $0.0 \mathrm{E}+00$ & & \\
\hline 9 & 0.009575 & 0.009575 & 0.009475 & 009475 & 0.05 & 0.09 & 0.00005 & $2.2 \mathrm{E}+05$ & $2.2 \mathrm{E}+05$ & 145.56 & 185 \\
\hline 10 & 0.009475 & 75 & 475 & 75 & 0.05 & .1 & 0.00005 & $.0 \mathrm{E}+00$ & $.2 \mathrm{E}+05$ & & \\
\hline 11 & 0.009575 & 0.009475 & 0.009475 & 0.009575 & 0.045 & 0.09 & 0.00005 & $2.2 \mathrm{E}+05$ & $0.0 \mathrm{E}+00$ & 144.57 & \\
\hline 12 & 0.009475 & 75 & & 75 & 0.05 & 0.09 & 0.00 & $0.0 \mathrm{E}+00$ & $0.0 \mathrm{E}+00$ & & \\
\hline 13 & 0.009475 & 0.009475 & 0.009575 & 0.009475 & 0.045 & 0.1 & 0.00005 & $2.2 \mathrm{E}+05$ & $2.2 \mathrm{E}+05$ & 57 & 62 \\
\hline 14 & 0.009475 & 0.009 & 475 & 009575 & 0.05 & 0.09 & 0.00 & $.0 \mathrm{E}+00$ & $.2 \mathrm{E}+05$ & & \\
\hline 15 & 0.009575 & 0.009575 & 0.009475 & .009575 & 0.045 & 0.09 & 0.00009 & $0.0 \mathrm{E}+00$ & $0.0 \mathrm{E}+00$ & 16 & 84 \\
\hline 16 & 0.009475 & 0.009 & 575 & 75 & 0.05 & 0.09 & 0.00009 & $2.2 \mathrm{E}+05$ & $2.2 \mathrm{E}+05$ & & \\
\hline 17 & & & & & & & & & & & \\
\hline 18 & 0.009575 & 0.009475 & 0.009575 & .009575 & 0.045 & 0.09 & 0.00005 & $0.0 \mathrm{E}+00$ & $2.2 \mathrm{E}+05$ & 145.56 & 85 \\
\hline 19 & 0.009575 & 75 & & 75 & .05 & 1 & 0.00 & $0 \mathrm{E}+00$ & $2 \mathrm{E}+05$ & & \\
\hline 20 & 0.009575 & 0.009 & 475 & 75 & 0.045 & 0.1 & 0.00009 & $2.2 \mathrm{E}+05$ & $0.0 \mathrm{E}+00$ & 16.463 & 63 \\
\hline 21 & 09475 & 75 & & 75 & 0.045 & .1 & 000 & $2.2 \mathrm{E}+05$ & $0 \mathrm{E}+00$ & & \\
\hline 22 & 0.009575 & 75 & 75 & 75 & 0.045 & 0.1 & 0.0 & $0.0 \mathrm{E}+00$ & $2.2 \mathrm{E}+05$ & 396 & \\
\hline 23 & 0.009575 & 0.009 & 75 & 75 & 0.05 & 0.09 & 0.00 & $2.2 \mathrm{E}+05$ & $0.0 \mathrm{E}+00$ & 236 & 16 \\
\hline 24 & 0.009475 & 009475 & & 0.009 & 0.05 & & & $2.2 \mathrm{E}+05$ & $0.0 \mathrm{E}+00$ & & \\
\hline 25 & 0.009475 & 0.009575 & 475 & 0.009575 & 0.05 & 0.09 & 0.00005 & $0.0 \mathrm{E}+00$ & $2.2 \mathrm{E}+05$ & 16.616 & 984 \\
\hline 26 & 0.009475 & 09575 & 9475 & 75 & 0.05 & 0.1 & 0.00005 & $0.0 \mathrm{E}+00$ & $2.2 \mathrm{E}+05$ & & \\
\hline 27 & 0.009575 & 0.009475 & 75 & 75 & 0.05 & 0.09 & 0.0 & $2.2 \mathrm{E}+05$ & $0.0 \mathrm{E}+00$ & .56 & 85 \\
\hline 28 & 0.009575 & 75 & & 75 & 0.045 & 0.1 & 0.00 & $2.2 \mathrm{E}+05$ & $2.2 \mathrm{E}+05$ & & \\
\hline 29 & 0.009575 & 0.009575 & & 0.009475 & 0.045 & 0.09 & 0.00009 & $2.2 \mathrm{E}+05$ & $2.2 \mathrm{E}+05$ & 21 & 174 \\
\hline 30 & 0.009575 & 0.00 & & 75 & 0.045 & 0.09 & 09 & $0.0 \mathrm{E}+00$ & $0.0 \mathrm{E}+00$ & & \\
\hline 31 & 0.009575 & 0.009575 & 0.009475 & 0.009475 & 0.05 & 0.1 & 0.00009 & $2.2 \mathrm{E}+05$ & $0.0 \mathrm{E}+00$ & 395 & 38 \\
\hline 32 & 0.009575 & 0.009575 & 0.009575 & 0.009475 & 0.045 & 0.1 & 0.00009 & $0.0 \mathrm{E}+00$ & $0.0 \mathrm{E}+00$ & & 262.112 \\
\hline 33 & 0.009475 & 0.009575 & 0.009575 & 0.009575 & 0.045 & 0.1 & 0.00005 & $0.0 \mathrm{E}+00$ & $0.0 \mathrm{E}+00$ & 43.989 & 311.966 \\
\hline 34 & 0.009575 & 0.009475 & 0.009475 & 0.009475 & 0.05 & 0.1 & 0.00009 & $0.0 \mathrm{E}+00$ & $2.2 \mathrm{E}+05$ & 16.396 & 324.409 \\
\hline 35 & 0.009475 & 0.009575 & 0.009575 & 0.009475 & 0.05 & 0.1 & 0.00005 & $0.0 \mathrm{E}+00$ & $2.2 \mathrm{E}+05$ & 16.236 & 310.516 \\
\hline 36 & 0.009575 & 0.009475 & 0.009575 & 0.009475 & 0.05 & 0.09 & 0.00005 & $2.2 \mathrm{E}+05$ & $0.0 \mathrm{E}+00$ & 145.56 & 14.1185 \\
\hline 37 & 0.009475 & 0.009575 & 0.009475 & 0.009575 & 0.045 & 0.1 & 0.00005 & $0.0 \mathrm{E}+00$ & $2.2 \mathrm{E}+05$ & 43.989 & 311.966 \\
\hline 38 & 0.009475 & 0.009475 & 0.009575 & 0.009575 & 0.045 & 0.09 & 0.00009 & $0.0 \mathrm{E}+00$ & $0.0 \mathrm{E}+00$ & 16.395 & 324.338 \\
\hline
\end{tabular}




\begin{tabular}{c|c|c|c|c|c|c|c|c|c|c|c}
\hline & $\boldsymbol{d} \boldsymbol{1}$ & $\boldsymbol{d} \mathbf{2}$ & $\boldsymbol{d 3}$ & $\boldsymbol{d} \boldsymbol{4}$ & $\boldsymbol{L b}$ & $\boldsymbol{C b}$ & $\boldsymbol{D b}$ & $\boldsymbol{K y y}$ & $\boldsymbol{K z z}$ & $\boldsymbol{F R Q} \mathbf{i m g}$ & $\boldsymbol{F R Q} \boldsymbol{r e a l}$ \\
\hline $\mathbf{3 9}$ & 0.009475 & 0.009475 & 0.009475 & 0.009575 & 0.045 & 0.1 & 0.00005 & $0.0 \mathrm{E}+00$ & $0.0 \mathrm{E}+00$ & 16.616 & 323.984 \\
\hline $\mathbf{4 0}$ & 0.009575 & 0.009575 & 0.009575 & 0.009575 & 0.045 & 0.1 & 0.00009 & $0.0 \mathrm{E}+00$ & $0.0 \mathrm{E}+00$ & 16.396 & 324.409 \\
\hline $\mathbf{4 1}$ & 0.009475 & 0.009475 & 0.009575 & 0.009475 & 0.045 & 0.1 & 0.00005 & $2.2 \mathrm{E}+05$ & $2.2 \mathrm{E}+05$ & 142.21 & 13.7369 \\
\hline $\mathbf{4 2}$ & 0.009475 & 0.009575 & 0.009575 & 0.009475 & 0.05 & 0.09 & 0.00009 & $0.0 \mathrm{E}+00$ & $2.2 \mathrm{E}+05$ & 16.395 & 324.338 \\
\hline $\mathbf{4 3}$ & 0.009575 & 0.009475 & 0.009475 & 0.009575 & 0.045 & 0.09 & 0.00005 & $2.2 \mathrm{E}+05$ & $0.0 \mathrm{E}+00$ & 144.57 & 13.9962 \\
\hline $\mathbf{4 4}$ & 0.009475 & 0.009475 & 0.009475 & 0.009475 & 0.045 & 0.09 & 0.00009 & $0.0 \mathrm{E}+00$ & $0.0 \mathrm{E}+00$ & 44.548 & 325.565 \\
\hline $\mathbf{4 5}$ & 0.009575 & 0.009475 & 0.009575 & 0.009475 & 0.05 & 0.09 & 0.00009 & $2.2 \mathrm{E}+05$ & $2.2 \mathrm{E}+05$ & 144.9 & 13.8962 \\
\hline $\mathbf{4 6}$ & 0.009475 & 0.009475 & 0.009475 & 0.009475 & 0.05 & 0.09 & 0.00009 & $2.2 \mathrm{E}+05$ & $0.0 \mathrm{E}+00$ & 16.617 & 324.052 \\
\hline $\mathbf{4 7}$ & 0.009575 & 0.009475 & 0.009475 & 0.009575 & 0.05 & 0.1 & 0.00009 & $2.2 \mathrm{E}+05$ & $0.0 \mathrm{E}+00$ & 16.616 & 323.984 \\
\hline $\mathbf{4 8}$ & 0.009475 & 0.009475 & 0.009575 & 0.009475 & 0.045 & 0.09 & 0.00005 & $2.2 \mathrm{E}+05$ & $0.0 \mathrm{E}+00$ & 142.21 & 13.7369 \\
\hline
\end{tabular}

\subsection{Mathematical model equation}

To build the model equation representing the relationship between the frequency (img-real) and the 9 factors studied, we use the regression coefficients shown in Tables 4 and 5. This model has been simplified, and the ranking of factors is done according to the diagram of Pareto (Figures 3 and 4).

FRQ img $=-2705+182863 \mathrm{~d} 1-1239 \mathrm{~d} 2+128641 \mathrm{~d} 3-4289$ $\mathrm{d} 4-897 \mathrm{Lb}-1733 \mathrm{Cb}+2952 \mathrm{Db}+0.000226 \mathrm{Kyy}+0.000252$ $\mathrm{Kzz}$

FRQ real $=7438-427644 \mathrm{~d} 1-204 \mathrm{~d} 2-350633 \mathrm{~d} 3-9860$ d4 + 1862 Lb+ 4039 Cb- 98695 Db- 0.000675 Kyy- 0.000721 $\mathrm{Kzz}$

\section{- Optimization method}

To enhance the seven remaining response factors, the values are set to $\mathrm{P}<0.05$, the red reference line was changed to zero by moving manually the columns of the base design matrix, maintaining the corresponding frequency values for each row, and keeping the matrix balanced until building a final matrix as shown in Table 6 [18].

The goal is therefore to find the optimal polynomial equation. From the previous statistical analysis, eliminating the quadratic terms yields a new well-fitting model. The results are presented in Tables 7 and 8 .

Table 7. Factorial Regression: FRQ img versus d1; d2; d3 d4; Lb; Cb; Db; Kyy; Kzz

\begin{tabular}{c|c|c|c|c|c}
\hline Source & DF & Adj SS & Adj MS & F-Value & P-Value \\
\hline Model & 9 & 142685 & 15853.9 & 97.80 & 0.000 \\
\hline Linear & 9 & 142685 & 15853.9 & 97.80 & 0.000 \\
\hline D1 & 1 & 22047 & 22044.9 & 135.99 & $\mathbf{0 . 0 0 0}$ \\
\hline D2 & 1 & 3084 & 3083.6 & 19.02 & $\mathbf{0 . 0 0 0}$ \\
\hline D3 & 1 & 7235 & 7235.1 & 44.63 & $\mathbf{0 . 0 0 0}$ \\
\hline D4 & 1 & 6476 & 6476.2 & 39.95 & $\mathbf{0 . 0 0 0}$ \\
\hline Lb & 1 & 17393 & 17393.5 & 107.30 & $\mathbf{0 . 0 0 0}$ \\
\hline Cb & 1 & 15817 & 15816.9 & 97.57 & $\mathbf{0 . 0 0 0}$ \\
\hline Db & 1 & 32677 & 32677.4 & 201.58 & $\mathbf{0 . 0 0 0}$ \\
\hline kyy & 1 & 15627 & 15627.0 & 96.40 & $\mathbf{0 . 0 0 0}$ \\
\hline kzz & 1 & 10429 & 10429.3 & 64.34 & $\mathbf{0 . 0 0 0}$ \\
\hline error & 38 & 6160 & 162.1 & & \\
\hline Total & 47 & 148845 & & & \\
\hline & \multicolumn{7}{|l}{}
\end{tabular}

- $\quad$ Model Summary

$\begin{array}{clrc}\text { S } & \text { R-sq } & \text { R-sq (adj) } & \text { R-sq (pred) } \\ 12.7320 & 95.86 \% & 94.88 \% & 93.37 \%\end{array}$

- Regression Equation in Uncoded Units
FRQ img = -1947 + $461686 \mathrm{~d} 1-166044 \mathrm{~d} 2+256755 \mathrm{~d} 3-$ 255436 d4- 8302 Lb- 3822 Cb- 1379219 Db+ 0.000180 Куу $+0.000141 \mathrm{Kzz}$

- $\quad$ Fits and Diagnostics for Unusual Observations

$\begin{array}{ccccc}\text { Obs } & \text { FRQ img } & \text { Fit } & \text { Resid } & \text { Std Resid } \\ 35 & 16.24 & 41.07 & -24.84 & -2.13 \mathrm{R}\end{array}$

Table 8. Factorial Regression: FRQ real versus d1; d2; d3; d4; Lb; Cb; Db; Kyy; Kzz

\begin{tabular}{c|c|c|c|c|c}
\hline Source & DF & Adj SS & Adj MS & F-Value & P-Value \\
\hline Model & 9 & 943547 & 104839 & 409.14 & $\mathbf{0 . 0 0 0}$ \\
\hline Linear & 9 & 943547 & 104839 & 409.14 & $\mathbf{0 . 0 0 0}$ \\
\hline D1 & 1 & 158263 & 158263 & 617.64 & $\mathbf{0 . 0 0 0}$ \\
\hline D2 & 1 & 27375 & 27375 & 106.84 & $\mathbf{0 . 0 0 0}$ \\
\hline D3 & 1 & 38406 & 38406 & 149.88 & $\mathbf{0 . 0 0 0}$ \\
\hline D4 & 1 & 46773 & 46773 & 182.54 & $\mathbf{0 . 0 0 0}$ \\
\hline Lb & 1 & 112402 & 112402 & 438.66 & $\mathbf{0 . 0 0 0}$ \\
\hline Cb & 1 & 75656 & 75656 & 295.25 & $\mathbf{0 . 0 0 0}$ \\
\hline Db & 1 & 193402 & 193402 & 754.77 & $\mathbf{0 . 0 0 0}$ \\
\hline kyy & 1 & 123233 & 123233 & 480.93 & $\mathbf{0 . 0 0 0}$ \\
\hline kzz & 1 & 67846 & 67846 & 264.78 & $\mathbf{0 . 0 0 0}$ \\
\hline error & 38 & 9737 & 256 & & \\
\hline Total & 47 & 104 & & & \\
\hline
\end{tabular}

- Model Summary

$\begin{array}{cccc}\text { S } & \text { R-sq } & \text { R-sq (adj) } & \text { R-sq (pred) } \\ 16.0075 & 98.98 \% & 98.74 \% & 98.37 \%\end{array}$

- Regression Equation in Uncoded Units

FRQ real $=4452-1237034 \mathrm{~d} 1+494735 \mathrm{~d} 2-591557 \mathrm{~d} 3+$ $686467 \mathrm{~d} 4+21104 \mathrm{Lb}+8358 \mathrm{Cb}+3355373 \mathrm{Db}-0.000506$ Kуy $-0.000360 \mathrm{Kzz}$

- $\quad$ Fits and Diagnostics for Unusual Observations

$\begin{array}{ccccc}\text { Obs } & \text { FRQ real } & \text { Fit } & \text { Resid } & \text { Std Resid } \\ 45 & 13.90 & 54.53 & -40.63 & -2.81 \mathrm{R}\end{array}$

The employed model incorporates both principal effects and two-way interaction. We employed the values of (P) to estimate the coefficients and effects. To find the main effects using $\alpha=0.05$, the principal effects of diameter values of D1 to kzz and their interactions which are statistically important; where their $(\mathrm{P})$ values are lesser than 0.05 .

\section{The imaginary part}

Diameter d1 and Stiffness kzz, kyy and their related interactions are all important $\alpha=0.05$ (see Figure 6). 


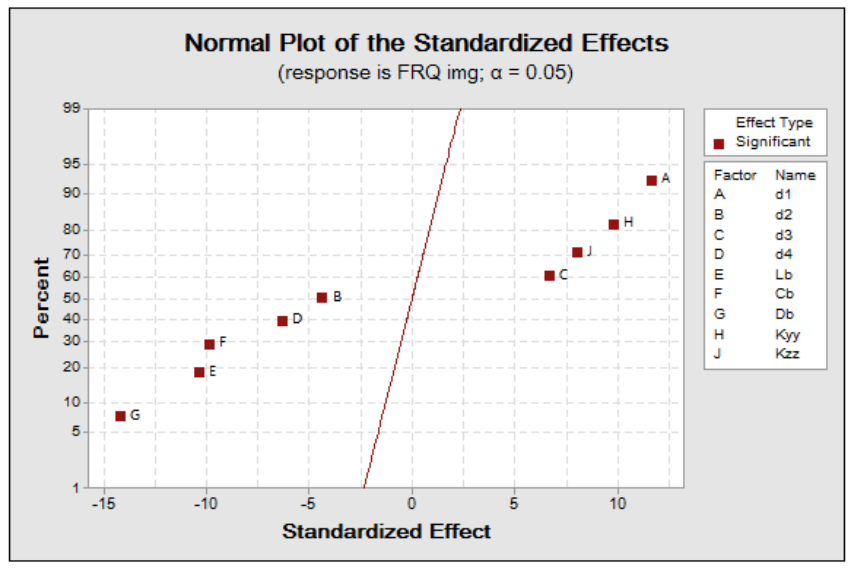

Figure 6. Representation of the standardized effects as an imaginary part

The hydrodynamic bearings dimensions of $\mathrm{Db}, \mathrm{Lb}, \mathrm{Cb}$ and their linked interactions are all important $(\alpha=0.05)$ (see Figure 7).

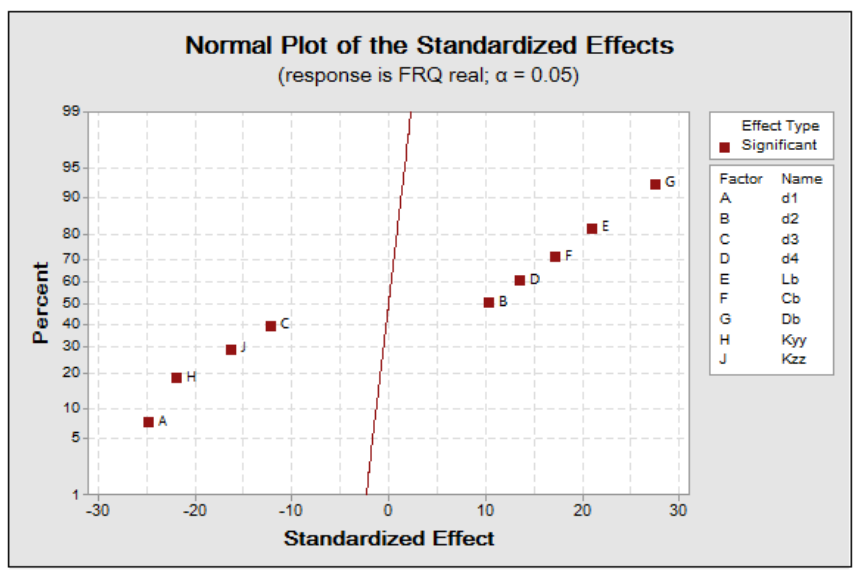

Figure 7. Representation of the standardized effects as a real part

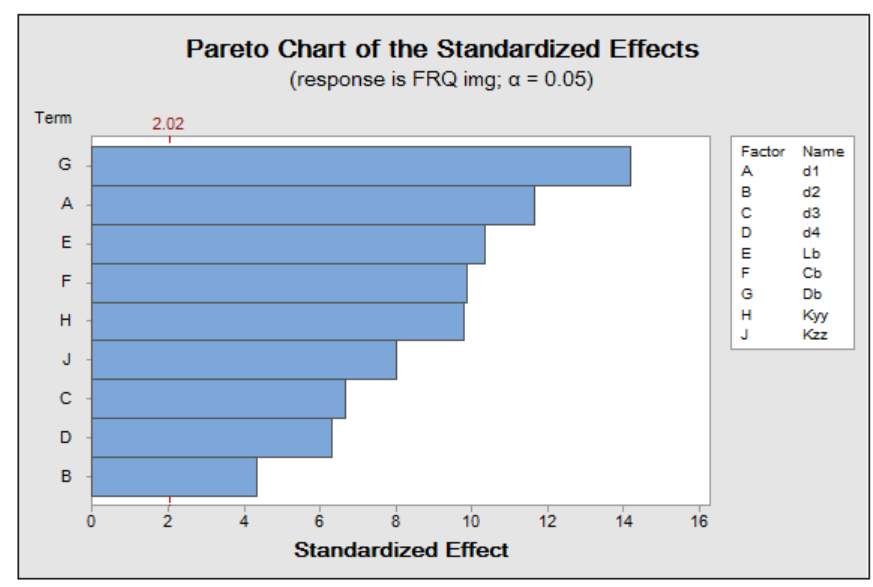

Figure 8. Pareto chart of the standardized effects- imaginary part

We note that it is the factor that positively affects the frequency in the imaginary part has negatively affected the frequency in the real part.

The effects absolute values are displays by Minitab on the Pareto chart (see Figures 8,9). All effects behind the reference line are significant at the level of 0.05 , in the imaginary part. The diameter $\mathrm{D}_{1}$ and stiffness kyy are all important $(\alpha=0.05)$, in the real part we find the opposite. $\mathrm{Db}$ and $\mathrm{Lb}$ all important $(\alpha=0.05)$.

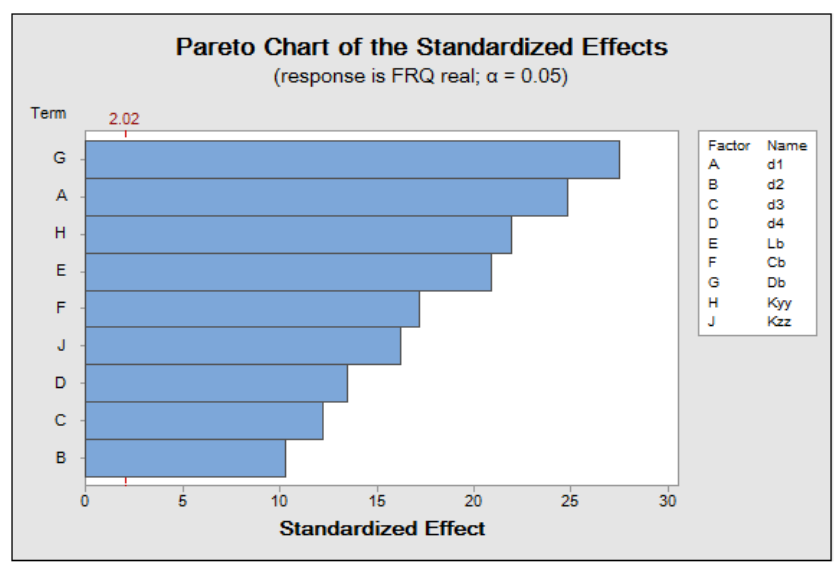

Figure 9. Pareto chart of the standardized effects- real part

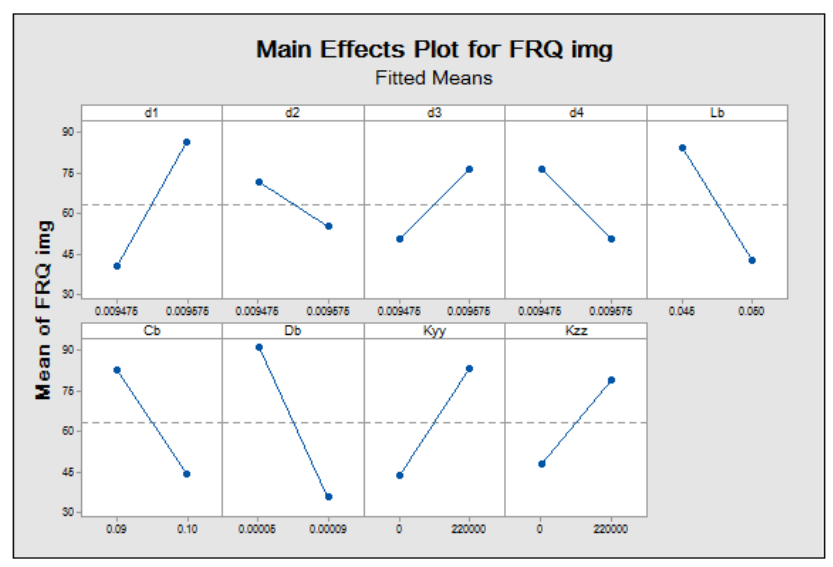

Figure 10. Main effects plot for frequency- imaginary part

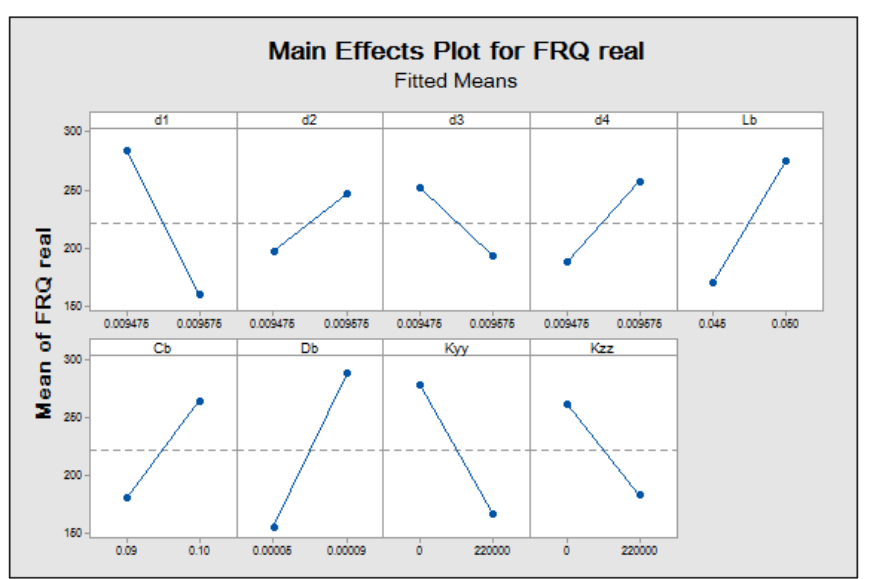

Figure 11. Main effects plot for frequency- real part

Then, the principal effect plots are sketched in MINITAB 17 as illustrated in Figures 10 and 11. The different diameters effects, the stiffness, and the hydrodynamic bearing dimensions on the excitation frequency show:

\section{- For imaginary part}

The diameter $\mathrm{d} 1$ and the stiffness kzz, kyy have significant effect where they augment the excitation frequency. The plot also reports that:

- The diameter d1 has more influence on the frequency compared to the stiffness kzz, kyy. 
- The other hydrodynamic bearing diameters and dimensions of ( $\mathrm{Lb}, \mathrm{Db}$, and $\mathrm{Cb}$ ) don't have an important effect on the excitation frequency.

\section{- $\quad$ For real part}

The hydrodynamic bearing dimensions of $(\mathrm{Db}, \mathrm{Lb}$, and $\mathrm{Cb}$ ) and diameters of D4 and D2 have significant effect where they augment the excitation frequency. The plot also reports that:

- The hydrodynamic bearing dimensions of $(\mathrm{Db}, \mathrm{Lb}$, and $\mathrm{Cb})$ have significant effect on the frequency compared to the diameters D4 and D2.

- The other diameters and the stiffness don't have a significant effect on the excitation frequency.

An improvement chart gives the effect of each factor (columns) on responses (rows) (Figure 12). The vertical red lines on the graph represent the current operator settings. The numbers displayed above the column indicate the current factor level settings (red color). The blue horizontal lines and numbers represent responses to the current factor level.

Minitab calculates in the imaginary part the diametre $\mathrm{d} 1$ and kzz are manimized when all factors are at their highest settings (d1=0,0096, kzz=195555,556).

In real part the hydrodynamic bearing dimensions of $(\mathrm{Db}$, $\mathrm{Lb}$, and $\mathrm{Cb}$ (and diameters of D4 and D2, are manimized when all factors are at their Its lowest settings $(\mathrm{Db}=0.0001$, $\mathrm{Lb}=0.0450, \mathrm{Cb}=0.090, \mathrm{D} 4=0.0095, \mathrm{D} 2=0.0095)$.
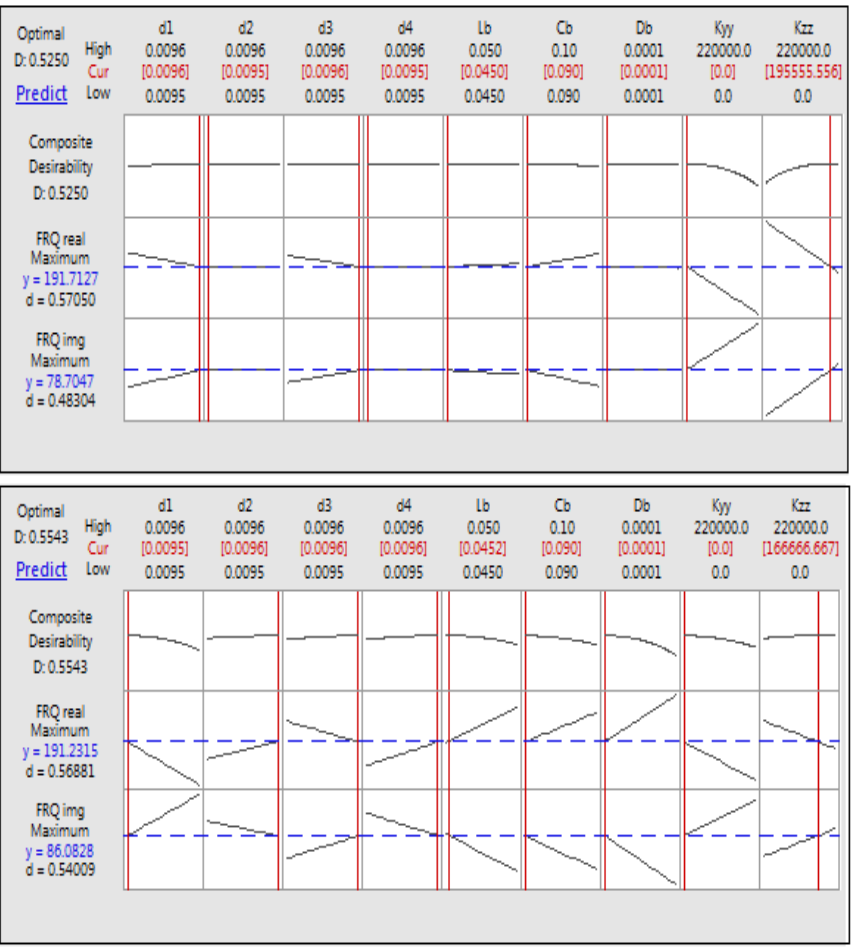

Figure 12. Optimum solution for nine factors

You like to see how the responses change when the stiffness $\mathrm{kzz}=166666.667$. In interactive mode, you can move the factor level (red) line for stiffness kzz, or enter 166666.667 in the stiffness kzz.The graphic shows that the expected response in the imaginary part (86.0828) and the expected response in the real part (191.2315).

Pareto charts Figure 13 are a type of bar chart in which the horizontal axis represents attributes of interest, rather than a continuous scale. Typically, these features are "disadvantages".
When arranging bars from largest to smallest, a Pareto chart can help you identify errors that are made up of a small number of vital elements and which are of little significance. The Cumulative Percentage line helps you determine the added contribution of each of the categories. Pareto Charts can also help focus improvement efforts on areas where the greatest gains can be made.

\section{a- The imaginary part:}

The vital few shortness in the imaginary part is represented by the following values of the imaginary frequency (Figure 13).

FRQ img $=142.210$, FRimg $=142.60$, FRQ img $=144.570$

FRQ img $=144.900$, FRimg $=145.210$, FRimg $=145.560$

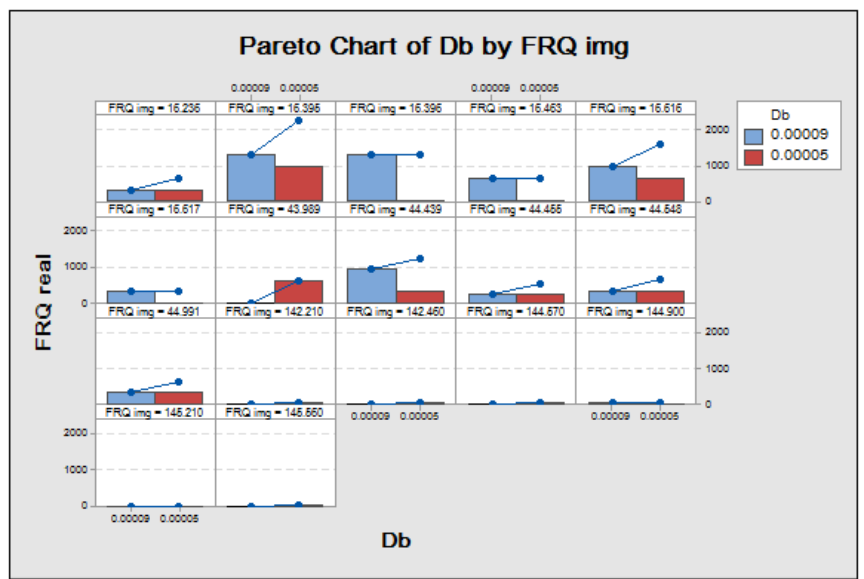

Figure 13. Pareto charts " imaginary part"

\section{b-The real part:}

The vital few shortness in the real part is represented by the following values of the real frequency (Figure 14).

FRQ real $=310.263$, FR real $=310.516$. FR real $=323.984$. FRQ real $=324.052$, FR real $=324.409$, FR real $=325.855$.

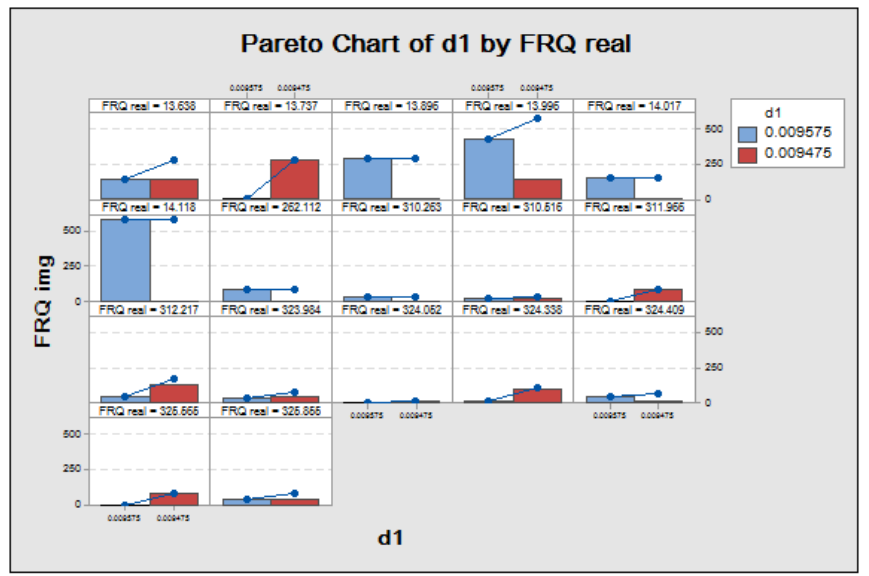

Figure 14. Pareto charts

After determining $\mathrm{d} 1$ as the main diameter affecting excitation frequency imaginary part, and the $\mathrm{Db}$ outer journal diameter as the main diameter affecting excitation frequency in real part, optimization charts are drawn based on values of frequencies obtained from matlab software. Figure 15 shows 
the model for rotor kit with various sections, disc and bearings. Figure 16 illustrates the Campbell diagram of the rotor-shaft system, where the shafts internal material damping is taken into consideration. The graph is plotted using the whirl frequencies (found from imaginary part of the eigenvalues), which are two positions, the first position in reverse rotation "BW", where the rotor rotates in the opposite direction. The second position is the rotation "FW", where the rotor rotates in the direction of rotation. The critical speed corresponding to the first position and the critical speed corresponding to the second position appear, the values of the first critical speeds identified.

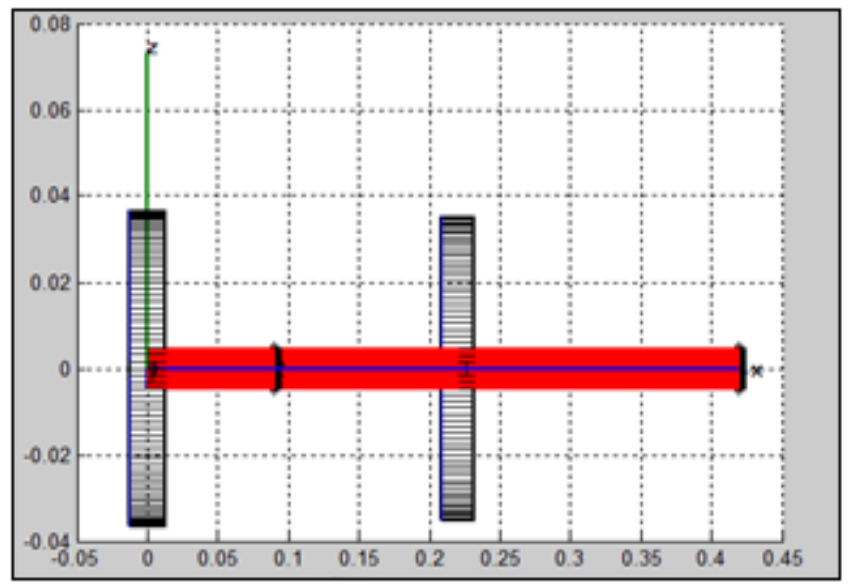

Figure 15. Rotor kit with various sections

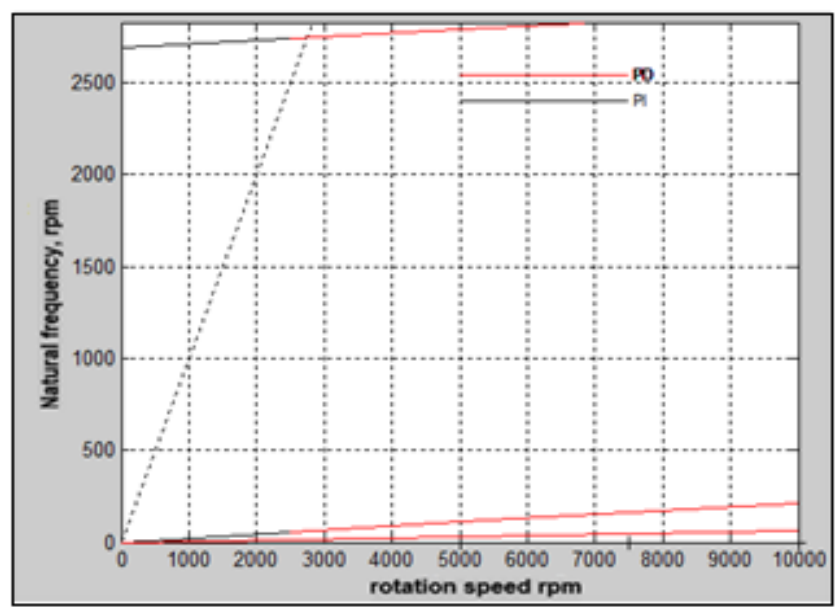

Figure 16. Campbell diagram

Critical speeds - Total number of modes studied 5 .

$\begin{array}{clc}\text { Mode } & (\mathrm{Hz}) & (\mathrm{rpm}) \\ 3 & 2.6233 \mathrm{e}-002 & 1.5740 \mathrm{e}+000 \\ 4 & 2.3259 \mathrm{e}-001 & 1.3955 \mathrm{e}+001 \\ 5 & 4.5778 \mathrm{e}+001 & 2.7467 \mathrm{e}+003\end{array}$

Figure 17 presents the evolution of the damping constant as a function of the rotational speed. Through the diagram, we notice that the values of the damping factor are negative and thus indicate that the rotor is stable.

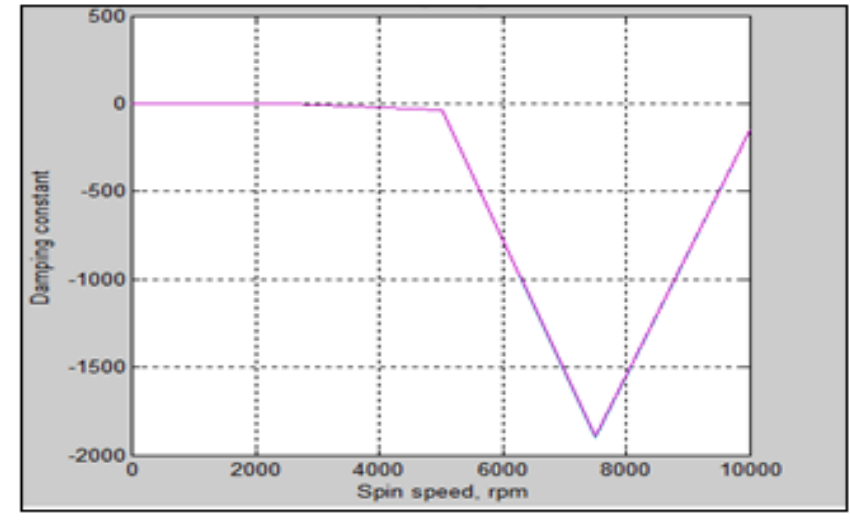

Figure 17. Stability diagram

Onset of instability speeds

$\begin{array}{ccc}\text { Mode } & (\mathrm{Hz}) & (\mathrm{rpm}) \\ 1 & 2.8279 \mathrm{e}+001 & 1.6967 \mathrm{e}+003 \\ 2 & 9.8980 \mathrm{e}+001 & 5.9388 \mathrm{e}+003 \\ 3 & 0.0000 \mathrm{e}+000 & 0.0000 \mathrm{e}+000 \\ 4 & 0.0000 \mathrm{e}+000 & 0.0000 \mathrm{e}+000 \\ 5 & 0.0000 \mathrm{e}+000 & 0.0000 \mathrm{e}+000\end{array}$

Table 9 gives the result of the shapes of the modes and the shape precession and the rotational speed for the modes correspondent to critical speeds. The modes 3, 4, 5, are direct precession (the rotor rotates in the direction of rotation).

Figure 18 gives relative deviation as a function of tree length and confirms the results obtained in Table 9.
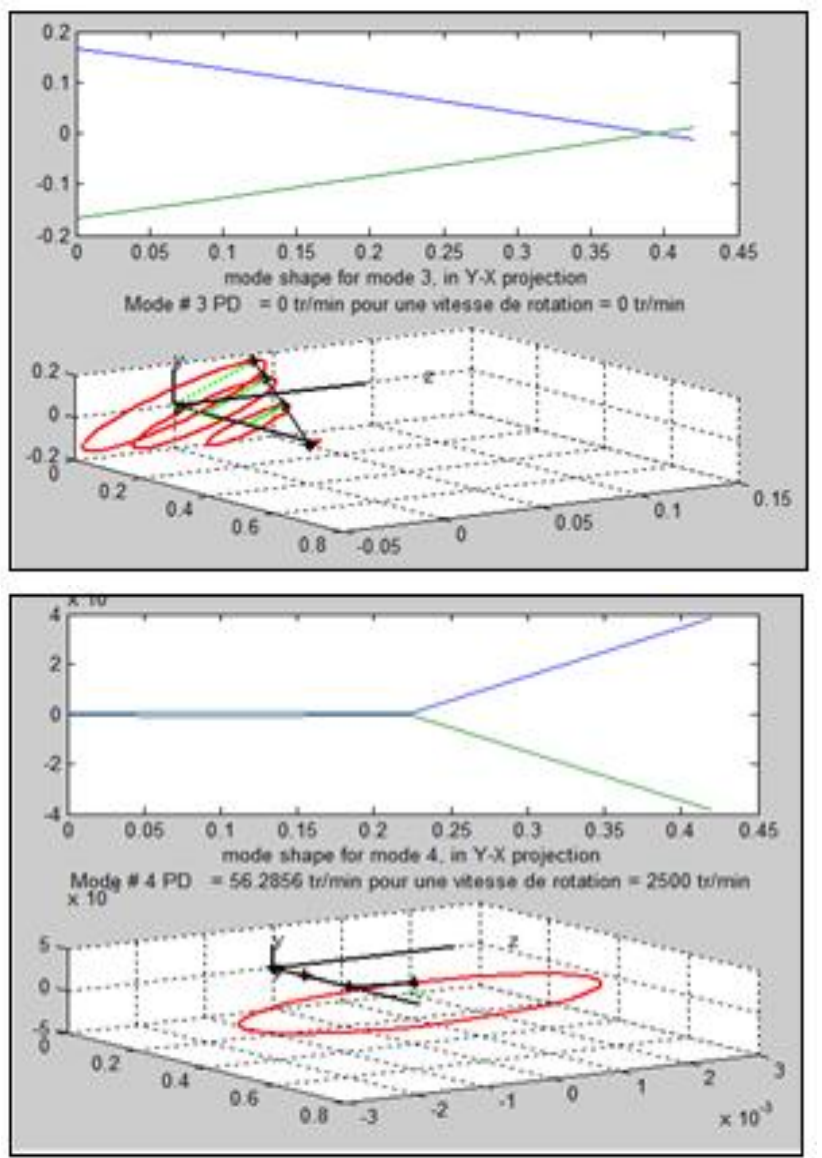


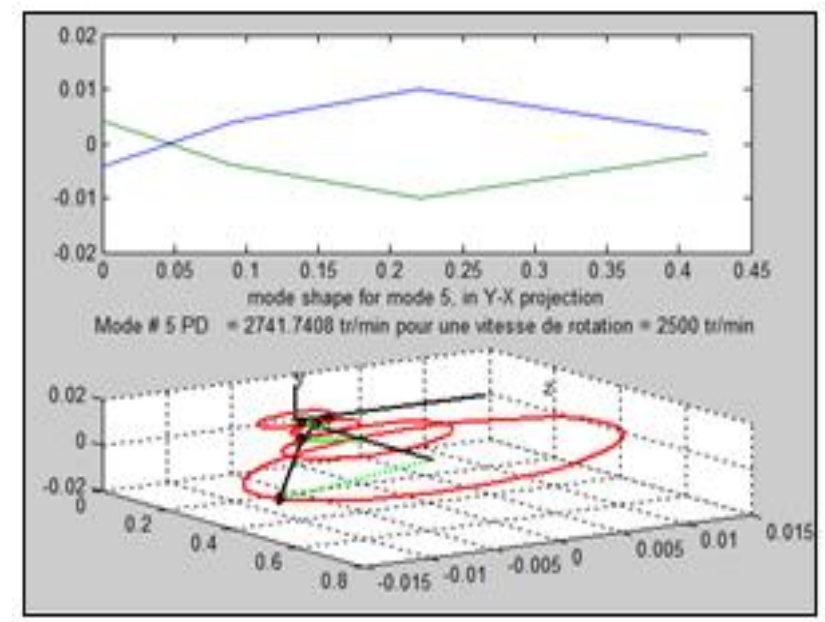

Figure 18. Forms of modes and precession of forms of modes at $0 \mathrm{rpm}$

Table 9. Forms of modes and precession of forms at $0 \mathrm{rpm}$

\begin{tabular}{c|c|c}
\hline Modes & Precession & Spin speed rpm \\
\hline 3 & direct & $0 \mathrm{rpm}$ \\
\hline 4 & direct & $\mathrm{FB}=56.2856 \mathrm{rpm}$ \\
\hline 5 & direct & $\mathrm{FB}=2741.7408 \mathrm{rpm}$ \\
\hline
\end{tabular}

\section{CONCLUSIONS}

The Plackett-Burman method in DOE and finite elements were employed to optimize the rotor and investigate the effects of the hydrodynamic bearings dimensions and the stiffness on the rotating machines dynamics and also to know the diameters which produce considerable effects on the excitation frequency as well as the reactions which can increase or decrease the principal effects and the gyroscopic effect on the eigenvalues of rotor-bearing systems. Our results show that:

-The diameter D1 has the more significant positive effect on the real part frequency which can be seen in the right of the response line compared to outer journal diameter $\mathrm{Db}$ that has a negative effect on the imaginary part frequency which is shown in the left of the response line and vice versa, as affirmed by the plot of principal effects.

-By the consideration of the internal material damping of the rotor. During the forward whirl, damping decreases, as the spin speed augments and in backward whirl, damping augments, as the spin speed augments. So, the system stability is determined. the stability of the system indicates the positive value of damping factor.

-For the system stability, it's required to be operated at a speed lesser than a critical speed. From the maximum real part vs the spin speed plot, the stability can be determined. It's concluded that the system is unstable for the positive value of the maximum real part, and it's stable for the negative value of the real part. As conclusion, the modal analysis is a main tool to get an important idea about the system dynamic behavior.

\section{REFERENCES}

[1] Childs, D. (1993). Turbomachinery Rotordynamics. John Wiley \& Sons, Inc, New York.
[2] Vance, J.M. (1988). Rotordynamics of Turbomachinery. John Wiley \& Sons, Inc, New York.

[3] Decaestecker, T.N., Lambert, W.E., Peteghem Carlos, H.V., Deforce, D., Van Bocxlaer, J.F. (2004). Optimization of solid-phase extraction for a liquid chromatographic-tandem mass spectrometric general unknown screening procedure by means of computational techniques. J Chrom A, 1056(1-2): 57-65. https://doi.org/10.1016/j.chroma.2004.06.010

[4] http://www.doesinc.com/knowledge.htm, accessed on Sep. 2006.

[5] Rao J.S. (1996). Rotor Dynamics. New Age International Publishers.

[6] Pilkey, W.D., Wang, B.P., Vannoy, D. (1976). Efficient optimal design of suspension systems for rotating shafts. J. Eng. Ind., 98(3): 1026-1029. https://doi.org/10.1115/1.3438996

[7] Bhat, R.B., Rao, J.S., Sankar, T.S. (1982). Optimum journal bearing parameters for minimum rotor unbalance response in synchronous whirl. J. Mech. Des., 104(2): 339-344. https://doi.org/10.1115/1.3256349

[8] Stocki, R., Szolc, T., Tauzowski, P. (2012). Robust design optimization of the vibrating rotor-shaft system subjected to selected dynamic constraints. Mech Syst Signal Process 2012; 29: 34-44. https://doi.org/10.1016/j.ymssp.2011.07.023

[9] Helfrich, R., Wagner, N. (2015). Application of optimization methods in rotor dynamics. In: Proceedings of the 9th IFToMM International Conference on Rotor Dynamics, pp. 1715-1725. https://doi.org/10.1007/9783-319-06590-8_141

[10] Yücel, E., Saruhan, H. (2017). Design optimization of rotor-bearing system considering critical speed using Taguchi method. Proc IMechE, Part E: J Process Mechanical Engineering, 231(2): 138-146. https://doi.org/10.1177/0954408915578581

[11] Jeffcott, H. (1919). The lateral vibration of loaded shaft in neighbourhood of a whirling speed - the effect of want of balance. Phil. Mag., 37: 304-314. https://doi.org/10.1080/14786440308635889

[12] Irretier, H. (1999). Mathematical foundations of experimental modal analysis in rotor dynamics. Mechanical Systems and Signal Processing, 13(2): 183191. https://doi.org/10.1006/mssp.1998.1215

[13] Rao J.S. (1996). Rotor Dynamics. New Age International Publishers.

[14] Choses, M., Dutt, J.K., Modak, S.V. (2012). Modal analysis of rotor-shaft system under the influence of rotor-shaft material damping and fluid film forces. Mechanism and Machine Theory, 48: 81-93. https://doi.org/10.1016/j.mechmachtheory.2011.09.001

[15] Forrai, L. (2000). A finite element model for stability analysis of symmetrical rotor systems with internal damping. Journal of Computational and Applied Mechanics, 1(1): 37-47.

[16] Fegade, R., Patel, V. (2013). Unbalanced response and design optimization of rotor by Ansys and design of experiments. International Journal of Scientific \& Engineering Research, 4(7).

[17] Fegade, R., Patel, V., Nehete, R.S., Bhandarkar, B.M. (2014). Unbalanced response of rotor using ansys parametric design for different bearings. International Journal of Engineering Sciences \& Emerging Technologies, 7(1): 506-515. 
[18] Mostefa, B., Kaddour, R., Mimoun, Y., Abdallah, N. (2018). Plackett-burman desing to study the influence of the stiffness of hydrodynamic bearings on the dynamic behaviour of turbo machinery. Mathematical Modelling of Engineering Problems, 5(4): 407-417. https://doi.org/10.18280/mmep.050418

[19] Naouri Abdallah Mostefa, B., Kaddour, R., Mimoun, Y. (2020). Investigate the effect of damping parameters of the hydrodynamic bearings using the optimization method of design of experiments. Mathematical Modelling of Engineering Problems, 7(1): 103-112. https://doi.org/10.18280/mmep.070113

[20] Someya, T. (ed). (1988). Journal-Bearing Databook. Springer, Berlin. https://doi.org/10.1007/978-3-64252509-4

[21] Atherton, D.P. (1975). Nonlinear Control Engineering. Van Nostrand Reinhold Company.

[22] Meirovitch, L. (1986). Elements of Vibration Analysis. Mac Graw Hill International Editions.

[23] Sino, R. (2007). Comportement dynamique et stabilité des rotor: application aux rotors composites. Thèse doctorat INSA Lyon, P187.

[24] Dugundji, J., Wendelle. J.H. (1983). Some analysis methodes for rotating systems with periodic coefficient. American Institute of aeronautics journal, 21(6): 890-897. https://doi.org/10.2514/3.8167

[25] Meng, G., Gasch, R. (2000). Stability and stabillity degree of a cracked flexible rotor supported on journal bearing. Journal of Vibration and Acoustics, 122: 116125. https://doi.org/10.1115/1.568448

\section{NOMENCLATURE}

Lb
Db
Cb
Kyy, Kzz
Cyy, Czz
k1, k2
$\omega$
$\Omega$
$[$ K b]
$[C$ b]
DF
SS
MS
F
P
Secoff
S
Seq SS
Adj SS
F

length of bearings $[\mathrm{m}]$.

outer journal diameter $[\mathrm{m}]$.

bearing clearance $[\mathrm{m}]$.

stiffness coefficients

damping coefficients a gyroscopic effect stiffness

The speed of rotation of the shaft ( $\mathrm{rd} / \mathrm{s})$

angular velocity (shaft) (rd/s)

dimensionless stiffness coefficients.

dimensionless damping coefficients.

Degrees of freedom from each source

Sum of squares.

Mean squares.

Calculate by dividing the factor MS by error.

Use to determine whether a factor is signif.

Standard error of the coefficient.

Estimated standard deviation of the error.

Sequential sum of squares.

Adjusted sum of squares.

The degrees of freedom for the test 